UNIVERSIDADE DE SÃO PAULO

ESCOLA DE ENFERMAGEM

GIOVANA RIBAU PICOLO PERES

PREVALÊNCIA E FATORES ASSOCIADOS ÀS LESÕES POR FRICÇÃO EM IDOSOS DE INSTITUIÇÕES DE LONGA PERMANÊNCIA 
GIOVANA RIBAU PICOLO PERES

\section{PREVALÊNCIA E FATORES ASSOCIADOS ÀS LESÕES POR FRICÇÃO EM IDOSOS DE INSTITUIÇÕES DE LONGA PERMANÊNCIA}

Dissertação apresentada ao Programa de Pós Graduação em Enfermagem na Saúde do Adulto da Escola de Enfermagem da Universidade de São Paulo como parte dos requisitos para obtenção do título de Mestre em Enfermagem

Programa de Pós-Graduação em Enfermagem na Saúde do Adulto - PROESA

\section{Orientadora:}

Profa. Dra. Vera Lúcia Conceição de Gouveia Santos

São Paulo 
AUTORIZO A REPRODUÇÃO E DIVULGAÇÃO TOTAL OU PARCIAL DESTE TRABALHO, POR QUALQUER MEIO CONVENCIONAL OU ELETRÔNICO, PARA FINS DE ESTUDO E PESQUISA, DESDE QUE CITADA A FONTE.

Assinatura:

Data:

Peres, Giovana Ribau Picolo

Prevalência e fatores associados às lesões por fricção em idosos de instituições de longa permanência / Giovana Ribau Picolo Peres. São Paulo, 2014.

$75 \mathrm{p.}$

Dissertação (Mestrado) - Escola de Enfermagem da Universidade de São Paulo.

Orientadora: Prof.a Dr. a Vera Lucia Conceição de Gouveia Santos Área de concentração: Enfermagem na Saúde do Adulto

1. Prevalência. 2. Ferimentos e lesões. 3. Idosos. 4. Enfermagem em estomaterapia. I. Título. 
Nome: Giovana Ribau Picolo Peres

Título: Prevalência e fatores associados às lesões por fricção em idosos de instituições de longa permanência.

Dissertação apresentada ao Programa de Pós-Graduação em Enfermagem na Saúde do Adulto da Escola de Enfermagem da Universidade de São Paulo para obtenção do título de Mestre em Enfermagem.

Aprovado em:
1

\section{Banca Examinadora}

Prof. Dr. Instituição:

Julgamento: Assinatura:

Prof. Dr. Instituição:

Julgamento: Assinatura:

Prof. Dr. Instituição:

Julgamento: Assinatura: 


\section{DEDICATÓRIA}

Aos meus pais.

Ao meu irmão e sua família.

À minha linda Vovó Needa

Aos meus amores.

Aos meus bichos 


\section{AGRADECIMENTO}

À professora Vera pelo respeito, paciência e todos os ensinamentos compartilhados. Obrigada por acreditar!

À Dra Ana Amélia Camarano pela atenção e a juda com os cadastros das instituições de longa permanência para idosos (ILPI).

À Daniele Fernandes de Carvalho pelo email das ILPI.

Às Dras Silvia e Diba pelos apontamentos no exame de qualificação e pelas lições que levarei sempre comigo.

À Alline, minha grande amiga, pela paciência, pelos ensinamentos e pela ajuda nas formatações, tabelas e quadros.

Às amigas, Kelly e Ticiane, pela parceira e companheirismo em todos os momentos. Como sempre digo, "A amizade verdadeira levamos sempre conosco".

Ao Bernardo, pelas análises estatística e sua paciência comigo.

Às pessoas que um dia me incentivaram a realizar essa conquista.

Às diretorias das ILPI, por aceitarem participar do estudo, abrirem suas portas e contribuirem para a pesquisa em nosso país.

À todos os idosos que participaram desse estudo, pelo carinho comigo, por cada gesto e por fazerem parte dessa conquista.

Aos funcionários das ILPI, que me receberam com todo o carinho. 


\section{EPÍGRAFE}

"Agradeço todas as dificuldades que enfrentei; não fosse por elas, eu não teria saído do lugar, As facilidades nos impedem de caminhar. Mesmo as críticas nos auxiliam muito."

(Chico Xavier, 1971) 
Peres GRP. Prevalência e fatores associados às lesões por fricção em idosos de instituições de longa permanência [tese]. São Paulo: Escola de Enfermagem, Universidade de São Paulo, 2014.

\section{RESUMO}

Introdução: Lesão por fricção é uma ferida traumática, que ocorre principalmente nas extremidades de idosos. Objetivo: O objetivo do estudo foi identificar e analisar a prevalência de lesão por fricção e os fatores demográficos e clínicos associados a essa ocorrência, em pessoas idosas residentes em Instituições de Longa Permanência para Idosos. Métodos: Trata-se de um estudo epidemiológico, transversal, analítico, exploratório, com abordagem quantitativa, realizado em três instituições do município de São Paulo que aceitaram participar do estudo, dentre 135 contactadas previamente. Os dados foram coletados mediante consulta ao prontuário, entrevista com o próprio residente e/ou responsável e exame físico do idoso. Os residentes foram entrevistados e avaliados quanto aos aspectos sóciodemográficos e clínicos, condições da pele e quanto às características das lesões encontradas. Para a coleta de dados, empregaram-se os seguintes instrumentos: instrumento de coleta de dados sócio-demográficos e clínicos, Teste Mini Exame do Estado Mental, Escala de Katz e Sistema de Classificação STAR - Lesão por Fricção. Os dados foram analisados por meio de: teste exato de Fisher, teste de Wilcoxon-Mann-Whitney e modelo de regressão logística (backwardstepwise). Resultados: A amostra de 69 residentes foi composta predominantemente por mulheres $(51 / 73,91 \%)$, da raça branca $(50 / 72,46 \%)$, com média de 81 anos de idade $(\mathrm{DP}=9,30)$ e mediana 82 anos, com algum problema na marcha $(58 / 84,06 \%)$, redução ou ausência na acuidade visual $(56 / 81,16 \%)$, dependência para atividades básica de vida diária (52/75,36\%), comprometimento cognitivo $(51 / 73,91 \%)$, presença de incontinência $(45 / 65,22 \%)$ e algum grau de desnutrição (magreza $=26 / 37,69 \%$ ). Oito sujeitos apresentaram 13 lesões por fricção, implicando em prevalência global de 11,6\% para essa amostra, sendo de $22,22 \%$ para homens, $7,84 \%$ para mulheres e $10,00 \%$ para a raça 
branca. Onze $(84,6 \%)$ lesões localizaram-se nos membros inferiores, predominando aquelas de categoria $3(6 / 46,1 \%)$. Embora os grupos com e sem lesões por fricção tenham diferido quanto à presença de: hipertensão arterial sistêmica, alterações na marcha (principalmente cadeirantes), rigidez, acuidade visual diminuída, edema de membros inferiores, equimoses, hematoma, pele seca e descamativa, púrpura senil, curativos/ adesivos, dependência para as atividades básicas de vida diária e magreza, somente as presenças de hematoma (RC: 9,159 / p: 0,017) e púrpura senil (RC: 6,265 / p: 0,033) permaneceram no modelo final de regressão logíastica. Conclusão: A prevalência de lesão por fricção entre idosos institucionalizados foi de 11,6\%, comparável a escassos estudos internacionais realizados com pacientes hospitalizados. Os fatores associados à ocorrência de lesão por fricção, hematoma e púrpura senil, estão de acordo com a literatura sobre o tema. Ao tratar-se de estudo inédito em nosso meio, seus resultados contribuem para o diagnóstico situacional da ocorrência de lesão por fricção em idosos institucionalizados e para a necessidade de implantação de medidas preventivas em grupos vulneráveis como os idosos.

PALAVRAS CHAVES: Prevalência, Lesão por fricção, Idosos, Instituição de longa permanência para idosos, Enfermagem, Estomaterapia. 
Peres GRP. Prevalence and factors associated with skin tears in elderly long-stay institutions [thesis]. São Paulo: Escola de Enfermagem, Universidade de São Paulo, 2014.

\begin{abstract}
Introduction: Skin tear is a traumatic wound, which occurs mainly in the extremities of elderly. Objective: The study objective was to identify and analyze the prevalence of skin tears and demographic and clinical factors associated with its occurrence in institutionalized elderly. Methods: This is an epidemiological cross sectional analytical, exploratory study with a quantitative approach, performed in three nursing homes of São Paulo who agreed to participate in the study, among 135 ones previously contacted. Data were collected by records consultation, interview with the resident himself and /or care giver and physical examination of the elderly. Residents were interviewed and assessed for socio-demographic and clinical features, skin conditions and skin tears characteristics. The following tools were used for data collection: socio-demographic and clinical data, Mini Mental State Examination test, Katz index and STAR Classification System -Skin Tear. Data were analyzed using Fisher's exact test, Wilcoxon-MannWhitney test and logistic regression (backward stepwise). Results: The sample of 69 residents was mostly composed by women (51 / 73.91\%), Caucasians $(50 / 72.46 \%)$, mean age $81(\mathrm{SD}=9.30)$ and median 82 years old, some problem in mobility (gait) $(58 / 84.06 \%)$, visual acuity problems (56 / 81.16\%), dependence for activities of daily living (52/75.36\%), cognitive impairment $(51 / 73,91 \%)$, presence of incontinence $(45 / 65.22 \%)$ and some degree of malnutrition (underweight $=26 / 37.69 \%$ ). Eight subjects had 13 skin tears, resulting in an overall prevalence of $11.6 \%$ for this sample, and $22.22 \%$ for men, $7.84 \%$ for women and $10.00 \%$ for the caucasians. Eleven $(84.6 \%)$ skin tear were located in the lower limbs, predominantly category 3 skin tears $(6 / 46.1 \%)$. Although there were statistically significant differences between groups with and without skinj tears related to: arterial hypertension, mobility problems (especially wheelchair users), stiffness, decreased visual acuity, lower limb edema, ecchymosis, hematoma, dry and scaly skin, senile purpura, dressings / adhesives, dependence for activities of daily living and thinness, just the presence of hematoma (RC: 9,159 / p:0,017) and senile purpura ( RC: 6,265 / p: 0,033) remained after logistic regression analysis. Conclusion: The prevalence of skin tear among institutionalized elderly was $11.6 \%$, comparable to few international studies with hospitalized patients. The factors associated with the occurrence of skin tear, hematoma and senile
\end{abstract}


purpura, are consistent with the literature on the subject. When being unpublished study in our country, our results contribute to the situational analysis of the occurrence of skin tear in elderly nursing home residents and the need to implement preventive measures in vulnerable groups like the elderly.

KEYWORDS: Prevalence, skin tears, elderly, long-stay institutions, Nursing, Stomatherapy. 


\section{LISTA DE QUADROS}

QUADRO 1 - FATORES INTRÍNSECOS E EXTRÍNSECOS ASSOCIADOS AO AUMENTO DO RISCO PARA LF............................................................................... 24

QUADRO 2 - EQUAÇÕES PARA ESTIMATIVAS INDIRETAS DE PESO E

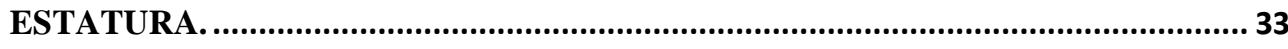

QUADRO 3 - CLASSIFICAÇÃO INTERNACIONAL DE IMC …………….............. 36

QUADRO 4- VARIÁVEIS DO ESTUDO................................................................. 38 


\section{LISTA DE TABELAS}

TABELA 1: DISTRIBUIÇÃO DA AMOSTRA SEGUNDO A ILPI. SÃO PAULO, 2013.

TABELA 2: DADOS SÓCIO-DEMOGRÁFICOS E CLÍNICOS DOS IDOSOS INSTITUCIONALIZADOS. SÃO PAULO, 2013. 42

TABELA 3: VARIÁVEIS QUANTITATIVAS DE ACORDO COM A PRESENÇA OU AUSÊNCIA DE LF. SÃO PAULO, 2013

TABELA 4: PREVALÊNCIA DE LF DE ACORDO COM A VARIÁVEL CATEGÓRICA. SÃO PAULO, 2013. .44

TABELA 5: FATORES ASSOCIADOS À OCORRÊNCIA DAS LF, SEGUNDO REGRESSÃO LOGÍSTICA. SÃO PAULO, 2013. .46 


\section{SUMÁRIO}

1. INTRODUÇÃ $O$............................................................................................. 15

1.1 CONCEITO E CARACTERÍSTICAS DAS LESÕES POR FRICÇÃO .................. 17

1.2 EPIDEMIOLOGIA DAS LESÕES POR FRICÇÃO ............................................... 19

1.3 FATORES ASSOCIADOS AO DESENVOLVIMENTO DE LESÃO POR

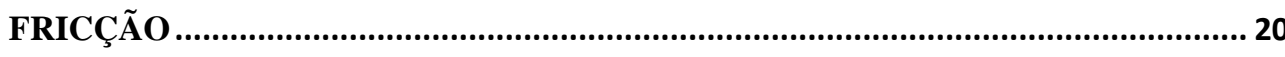

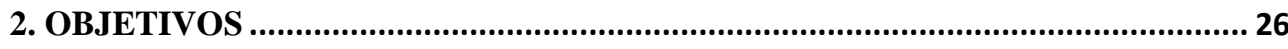

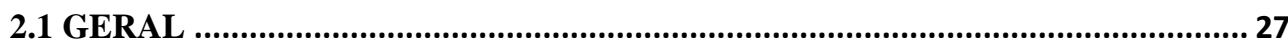

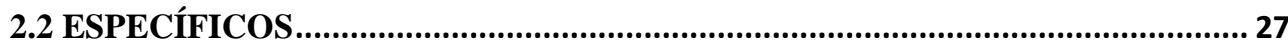

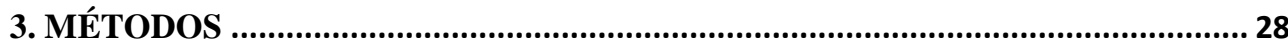

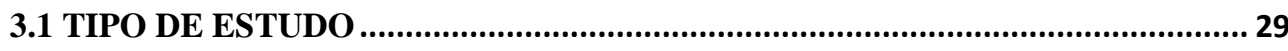

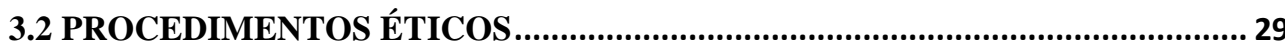

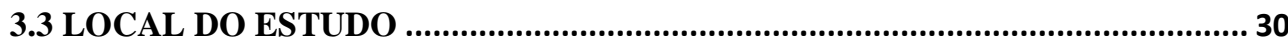

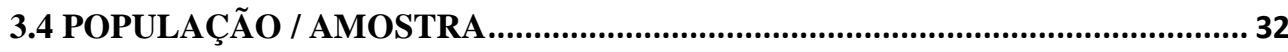

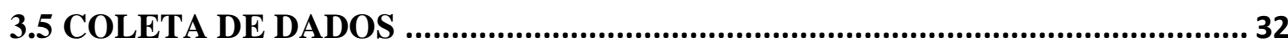

3.5.1 PROCEDIMENTOS PARA A COLETA DE DADOS........................................ 32

3.5.2 INSTRUMENTOS PARA A COLETA DE DADOS........................................... 35

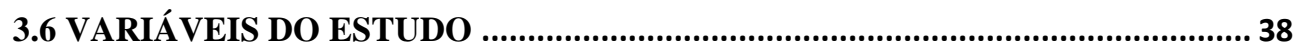

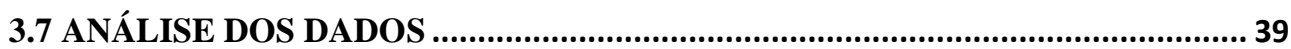

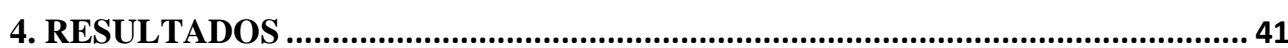

4.1 CARACTERIZAÇÃO DEMOGRÁGICA E CLÍNICA DA AMOSTRA............... 42

4.2 PREVALÊNCIA DE LF E FATORES ASSOCIADOS ........................................ 44

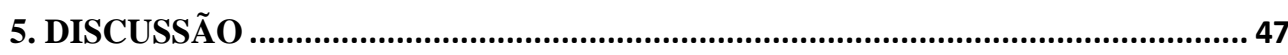

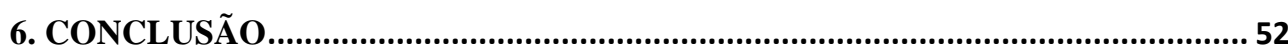

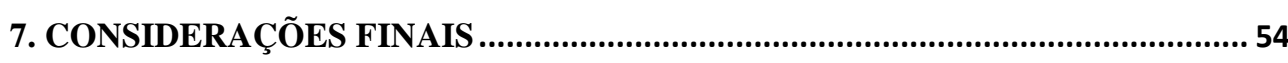

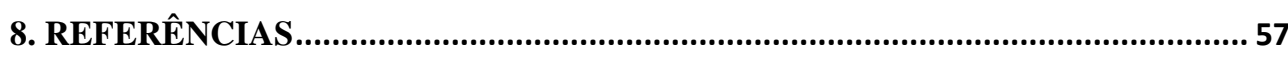

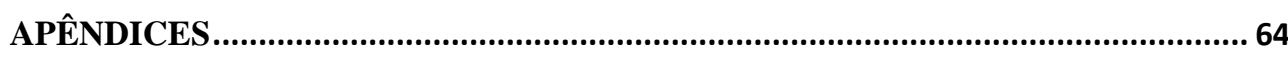

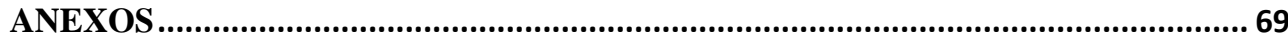


1. INTRODUÇÃO 


\section{INTRODUÇÃO}

Lesão por fricção (LF) é uma ferida traumática que ocorre principalmente nas extremidades de idosos, resultante de fricção ou de uma combinação de fricção e cisalhamento, levando à separação da epiderme e derme (feridas de espessura parcial) ou separando a epiderme e a derme das estruturas subjacentes (ferida de espessura total). ${ }^{1,2,3,4}$

Segundo alguns autores, ${ }^{2,5-8}$ esse tipo de lesão é mais frequente do que as Úlceras por Pressão (UP) e queimaduras.

Apesar da epidemiologia das LF ainda não estar bem definida na literatura, estudos internacionais apontam prevalências que variam de 5,5\% até $19,5 \%^{5,8-10}$, sendo os maiores coeficientes $\left(18,5 \%^{9}\right.$ e $\left.19,5 \%^{5}\right)$ encontrados entre os idosos.

Associadas principalmente à fragilidade cutânea, as LF são feridas comuns nessa população, podendo chegar a 1,5 milhão de lesões por ano em idosos institucionalizados. ${ }^{11}$ Estima-se que, até 2030, o número de indivíduos com alto risco para essas lesões será de 8,1 milhões de pessoas somente nos Estados Unidos. ${ }^{12}$

Em nosso país, esse tema ainda é bastante recente e pouco conhecido. Com o envelhecimento populacional - que o país já apresenta ${ }^{13}$ acredita-se que as LF também são bastante frequentes em nosso meio. No entanto, parecem permanecer despercebidas ou pouco valorizadas à medida que são compreendidas e vistas como inerentes à idade. ${ }^{14-16}$

A vulnerabilidade do idoso para o desenvolvimento de LF, a institucionalização dos idosos em organizações de longa permanência, prática também cada vez mais frequente em nosso meio, e o desconhecimento do tema no país motivaram a realização deste estudo epidemiológico sobre essas lesões. Espera-se que a presente investigação possa contribuir para a elucidação da prevalência desse tipo de ferida em idosos institucionalizados, fortalecendo o conhecimento nacional e internacional sobre o tema, além de ampliar a sua divulgação entre os profissionais de saúde no Brasil. 


\subsection{CONCEITO E CARACTERÍSTICAS DAS LESÕES POR FRICÇÃO}

Podem-se encontrar na literatura três definições semelhantes para LF. A primeira definição foi descrita por Payne e Martin, em 1990': "ferida traumática que ocorre principalmente nas extremidades de idosos, resultante de forças de cisalhamento ou fricção que separam a epiderme da derme". Pouco tempo depois, ao revisar esse conceito, os mesmos autores 17 estabeleceram que a LF é " uma ferida traumática que ocorre principalmente nas extremidades de idosos, resultante de forças de cisalhamento ou fricção, que separam a epiderme da derme (ferida de espessura parcial) ou que separam ambas, epiderme e derme, das estruturas subjacentes (ferida de espessura total)".

Em 2007, Carville e colaboradores ${ }^{2}$ publicaram um novo conceito baseado no proposto por Payne e Martin ${ }^{17}$ e que foi traduzido e adaptado para o Brasil por Strazzieri-Pulido e Santos: ${ }^{3,4}$ "LF é um tipo de ferida traumática que ocorre principalmente nas extremidades de idosos, resultante de fricção ou de uma combinação de fricção e cisalhamento, levando à separação da epiderme da derme (ferida de espessura parcial) ou separando totalmente a epiderme e a derme das estruturas subjacentes (ferida de espessura total)". $3,4,17$

Mais recentemente, e ainda de forma similar às anteriores, LeBlanc e colaboradores ${ }^{18}$ sugerem que as LF "resultam de cisalhamento, fricção ou trauma corto-contuso que causam a separação das camadas da pele. As subsequentes feridas são de espessura parcial ou total, dependendo do grau de dano tissular."

Assim como se encontram várias definições para LF, existem também alguns sistemas de classificação dessas lesões; nenhum dos quais, no entanto, é considerado padrão ouro, ou seja, aceito internacionalmente por um número maior de países.

Na década de 90 , Payne e Martin ${ }^{17}$ foram os pioneiros na proposição de um sistema de classificação de LF. Embora o sistema de classificação de 
Payne e Martin ${ }^{1}$ seja o mais utilizado, os próprios autores reconheceram sua fragilidade, uma vez que as propriedades de medida não foram atestadas. ${ }^{17}$ A partir dessa classificação, outros autores têm desenvolvido sistemas modificados. Assim, Carville et $\mathrm{al}^{2}$ desenvolveram o STAR- Skin Tear Classification System, que inclui cinco categorias de LF (1a, 1b, 2a, 2b e 3), baseadas na existência e viabilidade de um retalho de pele. $\mathrm{O}$ instrumento contem ainda um protocolo de tratamento tópico da ferida e da pele periferida, conforme a categoria de LF, e um glossário. É de fácil aplicação e pode ser utilizado em qualquer ambiente de cuidados e por qualquer profissional de saúde. Foi adaptado e validado para o Brasil por StrazzieriPulido e Santos, em $2010^{3,4}$.

Mais recentemente, em 2011, Leblanc et al $^{19}$ desenvolveram um novo sistema de classificação, similar ao STAR porém um pouco mais simples. Essa nova classificação denominada ISTAP Skin Tear Classification baseia-se somente na presença/ausência do retalho de pele e inclui três tipos de LF: sem perda da pele (Tipo 1); com perda parcial do retalho (Tipo 2) e com perda total do retalho (Tipo 3). ${ }^{19}$ Esse instrumento ainda não se encontra adaptado e validado no Brasil.

As LF são geralmente rasas, limitadas à derme e variam consideravelmente em tamanho, localização, profundidade do trauma e da perda de tecido. Uma das características principais é a presença de um retalho de pele epidérmico nas feridas de espessura parcial, ou dermoepidérmico, nas feridas de espessura total. ${ }^{1,17}$

Apesar de poderem localizar-se em qualquer parte do corpo, as LF apresentam-se, mais frequentemente, nos membros superiores (mãos e braços) e inferiores. Edwards et $\mathrm{al}^{6}$ mostram que $60 \%$ das LF são encontradas nos membros inferiores. Já Malone et al ${ }^{11}$ indicaram o antebraço como localização de $80 \%$ das lesões encontradas por eles. White et $\mathrm{al}^{20}$ atribuem a variação de localizações das lesões ao grau de dependência dos pacientes. Os pacientes dependentes apresentam-nas mais frequentemente nos membros superiores o que está, provavelmente, relacionado às atividades de vida diária e à necessidade de ajuda para 
transferências e locomoção. Já os pacientes independentes apresentam-nas mais frequentemente nos membros inferiores, associadas a problemas de locomoção, quedas, acuidade visual diminuída e diminuição da sensibilidade sensorial. ${ }^{11,20,21}$

\subsection{EPIDEMIOLOGIA DAS LESÕES POR FRICÇÃO}

A prevalência e a incidência das LF ainda não estão bem determinadas na literatura ${ }^{14}$, pois existem poucos estudos epidemiológicos sobre elas, a maioria proveniente da Austrália. Entretanto, conforme mencionado anteriormente, a experiência clínica dá fortes indícios de que elas são uma condição relevante e prevalente, especialmente entre os idosos. ${ }^{11,12,22,23}$

Quanto à incidência, alguns poucos estudos podem ser descritos. Payne e Martin ${ }^{1}$ obtiveram incidência de 2,23\% em estudo mais amplo, junto a 10 instituições asilares, com 896 leitos, em um período de cinco meses. Já Malone e colaboradores, em uma coorte retrospectiva, também em isntituições para idosos, obtiveram incidência de 0,92\%. ${ }^{11}$ Em estudo prospectivo realizado em uma instituição asilar para veteranos de guerra, McGough-Csarny e Kopac ${ }^{12}$ encontraram 154 LF entre os 154 residentes, durante seis meses de estudo; desses, 79,2\% apresentavam história prévia de LF. Em outros cenários, estudo único de Kennedy e colaboradores ${ }^{24}$ mostrou incidências de 2,1 em homens e 4,6 em mulheres, em uma unidade de atenção primária rural da Nova Zelândia. $11 \%$ de LF pré-tibiais aconteceram no inverno e $44 \%$ no verão.

Para a prevalência de LF, também se pôde constatar um número bastante reduzido de estudos ${ }^{5,8,9}$, mostrando maior variedade de coeficientes e cenários. Em estudo realizado ${ }^{5}$ com veteranos de guerra, em atendimento domiciliar, na Austrália, Carville e Smith mostraram 19,5\% de LF dentre todos os tipos de feridas. Ainda no mesmo país, McErlean e colaboradores ${ }^{9}$ constataram prevalência de $10,7 \%$ (20/ 187 pacientes) em pacientes de um hospital terciário. 
No Brasil, encontrou-se apenas um estudo publicado sobre o tema. Amaral, Strazzieri-Pulido e Santos $^{25}$ obtiveram prevalência de 3,3\% (5 pacientes) de $\mathrm{LF}$ em pacientes oncológicos hospitalizados $(\mathrm{N}=157)$. Desses pacientes, $60 \%$ tinham idade maior que 60 anos.

\subsection{FATORES ASSOCIADOS AO DESENVOLVIMENTO DE LESÃO POR FRICÇÃO}

As LF têm etiologia multifatorial. Em idosos, um dos aspectos mais importantes refere-se às condições da pele que, em função de seu envelhecimento, torna-se altamente vulnerável ao desenvolvimento de lesões em geral e, particularmente, das LF. 1,11,12,15,26-31

O envelhecimento é um processo normal, individual, gradativo, dinâmico, progressivo e irreversível, ligado intimamente a fatores biológicos, psíquicos e sociais, que atinge todos os seres humanos, caracterizando uma etapa de vida onde ocorrem modificações fisiológicas, bioquímicas e psicológicas consequentes à ação do tempo. ${ }^{32}$

Dentre as mudanças fisiológicas, o envelhecimento da pele é um processo complexo que atinge principalmente a derme. Há dois processos de envelhecimento que ocorrem simultaneamente. O primeiro é o processo de envelhecimento normal da pele, denominado intrínseco (cronossenescência). ${ }^{33} \mathrm{O}$ segundo é o extrínseco, resultante de fatores do meio ambiente, especialmente a exposição à radiação ultravioleta (actinossenescência). ${ }^{33}$ As alterações normais da pele ocorrem em todas as áreas, já as resultantes da radiação ultravioleta ocorrem normalmente no rosto, pescoço e dorso das mãos. ${ }^{34,35}$ Com o envelhecimento, a epiderme e a membrana basal tornam-se gradualmente mais finas, deixando a pele mais vulnerável a pequenos traumas e, consequentemente, às lesões em geral. A pele deixa de ser uma barreira mecânica efetiva. Os vasos sanguíneos tornam-se mais frágeis e surgem as púrpuras senis. Aumenta a queratinização prematura da epiderme e os cones epidérmicos alargam-se, ficando mais planos. Consequentemente, o sistema de ancoragem dermeepiderme torna-se menos resistente às forças de fricção e ao 
cisalhamento. ${ }^{11,26,27,34,36}$ Nessa população, a derme chega a perder $20 \%$ da sua espessura total e esse é um fator extremamente importante para o aspecto de pele de papel de seda, comum nos idosos, tornando-a cada vez mais frágil. Os fibroblastos passam a produzir menos colágeno do tipo I e mais do tipo III, tornando suas fibras rarefeitas. Há perda de força tênsil, resistência, elasticidade e extensibilidade da pele. Seu turgor também diminui, caracterizando uma pele mais desidratada e ressecada, devido à redução na produção de glândulas sebáceas e sudoríparas. A idade também interfere na tela subcutânea, que fica mais delgada e menos eficiente. ${ }^{26,36}$

Além das mudanças na pele, as condições dos idosos como o aumento de co-morbidades e de doenças crônicas, as demências, a imobilidade e os problemas de locomoção, as quedas, a acuidade visual diminuída, a desnutrição e a desidratação, a diminuição da capacidade cognitiva e a diminuição da sensibilidade sensorial, dentre outras, contribuem para a ocorrência das LF. 3,4,7,11,12,15,21,37-39

Embora a idade seja um fator fundamental na epidemiologia das LF, a literatura indica que outros fatores contribuem para a sua ocorrência:

- Sexo feminino: em seu estudo de incidência de LF em instituição de longa permanência para idosos (ILPI), Malone e colaboradores ${ }^{11}$ identificaram que, além da incidência global de LF aumentar significativamente com a idade, também aumentou para o sexo feminino em idade mais avançada. Outro estudo, ${ }^{24}$ mostrou que a incidência de LF foi bem maior entre as mulheres $(4,6 \%)$ comparativamente aos homens $(2,1 \%)$, sendo que essa diferença aumentou nas faixas etárias maiores. A maior predisposição das mulheres às LF pode estar relacionada à menor espessura da pele, tipicamente maior nos homens por conter mais colágeno.

- Imobilidade: estudos ${ }^{15,20}$ mostram que dificuldades na marcha e necessidade de auxílio para deambular estão associadas à LF. Cadeiras de rodas e traumas em objetos estão associadas a 50\% dos acidentes causadores das LF. ${ }^{1,31,40}$

- Ingestão nutricional inadequada: estudo epidemiológico sobre LF em idosos em atendimento domiciliário ${ }^{12}$ revelou que dos 61 pacientes com LF, 
$69 \%$ tinham valores de dosagem de albumina abaixo do normal nos seis meses antecedentes ao aparecimento de LF; os níveis de proteína estavam abaixo do normal em $22 \%$ de 50 pacientes; redução do apetite estava presente em $66,1 \%$ dos pacientes e $68,1 \%$ foram classificados como nutricionalmente comprometidos. Os idosos têm uma propensão a desnutrição e desidratação crônica por diversas razões: inapetência, restrição alimentar, dependência para alimentar-se sozinho e comprometimento cognitivo entre outros.

- História prévia de LF: estudos ${ }^{1,39}$ apontam que indivíduos que frequentemente apresentam LF, já as apresentaram anteriormente. Por exemplo, para McGough-Csarny e Kopac ${ }^{12}$, 79,2\% dos 154 residentes em uma instituição para veteranos de guerra apresentaram história prévia de LF. Outros autores ${ }^{20}$ relatam que é comum a presença de mais de uma LF em um mesmo indivíduo, registrando média de 2,67 LF por residente, em uma instituição de longa permanência para idosos.

- Comprometimento cognitivo: em estudo descritivo, ${ }^{15}$ durante seis meses de observação visando à proposição de um novo protocolo de tratamento, Meuleneire ${ }^{15}$ verificou 88 LF e que as chances de apresentá-las aumentaram na vigência de demência. Já McGough-Csarny e Kopac ${ }^{12}$ diagnosticaram demência em 77,3\% dos pacientes com LF. O projeto Saúde, Bem-Estar e Envelhecimento (SAE) de São Paulo, Brasil, verificou um aumento progressivo da deterioração cognitiva dos idosos com o aumento da idade. ${ }^{41}$

- Presença de equimoses: as equimoses têm sido apontadas como um fator de risco intrínseco para a ocorrência de LF. ${ }^{2,39}$ McGough-Csarny e Kopac ${ }^{12}$ identificaram equimoses em 53,6\% dos pacientes e 46,6\% apresentaram equimoses ou púrpura senil no local das LF.

- Deficiência visual: no mesmo estudo citado anteriormente, Meuleneire ${ }^{15}$ verificou que as chances de apresentar LF eram maiores na presença de acuidade visual diminuída. Segundo White et $\mathrm{al}^{20}$, residentes com acuidade visual diminuída foram aqueles que apresentaram maior número de LF em ambas as extremidades. 
- Uso prolongado de corticóide: Meuleneire ${ }^{15}$ e Everett e Powell ${ }^{22}$ também verificaram que o uso de corticóides aumentou as chances de ocorrência de LF, mesmo sem indicação de dose e tempo de uso.

- Dependência para as atividades de vida diária: estudos apontam que quanto maior a dependência para as atividades de vida diária, maior o risco para traumas e, consequentemente, maiores as chances de desenvolvimento de LF. McGough-Csarny e Kopac ${ }^{12}$ mostraram que $81,8 \%$ dos pacientes com LF eram totalmente dependentes de cuidados. No estudo de White et $\mathrm{al}^{20}{ }^{20}$ os residentes totalmente dependentes, que necessitaram de auxílio para as atividades básicas de vida diária, apresentaram grande número de LF, principalmente nas extremidades superiores. Elas ocorreram durante a rotina de prestação de cuidados, como vestir e tomar banho, e durante posicionamentos e transferências. Residentes confinados às cadeiras de rodas e poltronas reclináveis sofreram traumas em quinas de mesas, cadeiras, quadros e nos próprios descansos para os pés das cadeiras de rodas. Trilhos da cama, elevadores mecânicos e cadeiras de banho também foram apontados como fontes dessas lesões.

- Incontinência: a incontinência é um fator de risco para LF uma vez que a umidade acarreta a diminuição da tolerância tissular. Frequentemente, o idoso é rotulado como incontinente sem que qualquer tentativa seja feita para o esclarecimento do problema ou instituição de tratamento adequado. A perda do controle esfincteriano tem um grande impacto psicológico e social e, geralmente, contribui para a institucionalização dos idosos. ${ }^{42}$

- Utilização de órteses: vários autores ${ }^{11,20,31,40}$ apontam cadeiras de rodas como responsáveis por acidentes que levam às LF.

- Transferências e quedas: as transferências e quedas também são apontadas por vários autores ${ }^{11,31,40}$ como associadas ao desenvolvimento de LF. Malone e colaboradores ${ }^{11}$ relataram que transferências contribuíram para a ocorrência de quase $20 \%$ das LF, em seu estudo.

Em 2011, um painel denominado Skin Tear Advisory Painel, ${ }^{14}$ com 12 líderes de opinião reconhecidos internacionalmente, estabeleceu um 
consenso sobre prevenção, fatores de risco, avaliação e tratamento das LF. Nesse consenso, os especialistas determinaram vários fatores intrínsecos e extrínsecos que contribuem para a ocorrência de LF, alguns dos quais já descritos anteriormente. Os fatores do consenso são apresentados no Quadro 1. que inclui ainda os demais autores levantados neste capítulo.

\section{Quadro 1 - Fatores intrínsecos e extrínsecos associados ao aumento do risco para $\mathbf{L F}$.}

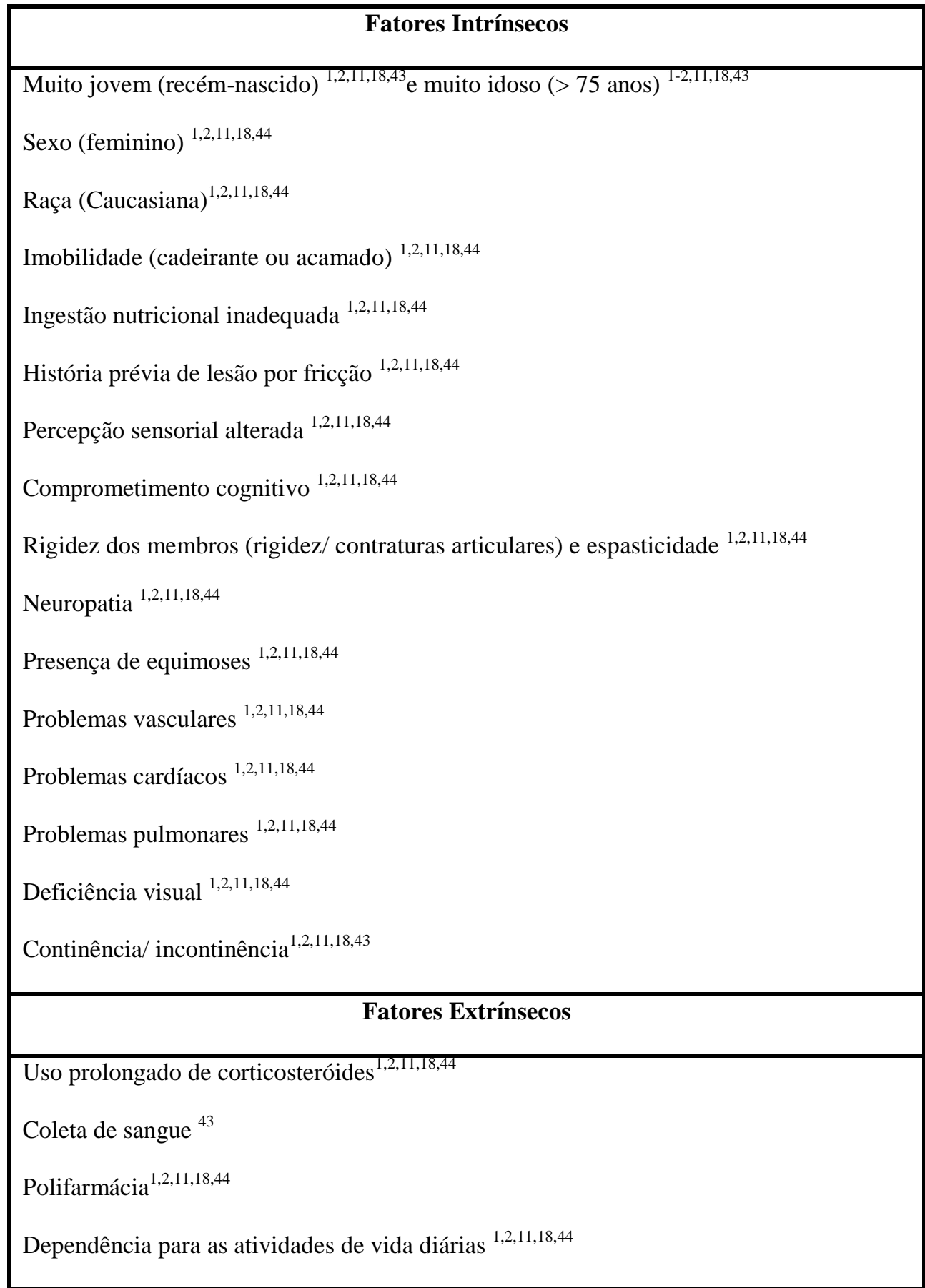


Utilização de órteses ${ }^{1,2,11,18,44}$
Ato de vestir e retirar meias ${ }^{1,2,11,18,44}$
Remover fitas e curativos adesivos ${ }^{1,2,11,18,44}$
Transferências e quedas $1,2,11,18,44$
Próteses $1,2,11,18,44$
Produtos destinados à limpeza da pele
Uso inadequado de barreiras protetoras de pele

Ressalta-se que, embora se trate de importante consenso internacional, muitos dos fatores mencionados no Quadro 1 baseiam-se somente na opinião dos especialistas, havendo repetição das publicações, nem sempre baseadas em revisões de literatura ou nas poucas evidências existentes sobre o tema. Dessa maneira, no presente estudo, explorar-se-ão somente as variáveis respaldadas nos restritos estudos exploratórios encontrados. 
2. OBJETIVOS 


\section{OBJETIVOS}

\subsection{GERAL}

- Identificar e analisar a prevalência de LF e os fatores demográficos e clínicos associados a essa ocorrência, em pessoas idosas residentes em Instituições de Longa Permanência para Idosos (ILPI).

\subsection{ESPECÍFICOS}

- Identificar as características sócio-demográficas e clínicas dos idosos nas diferentes ILPI;

- Identificar as características das LF, nos idosos institucionalizados;

- Verificar as associações entre a presença de LF e as características sócio-demográficas dos idosos institucionalizados; e

- Verificar as associações existentes entre a presença de LF e as características clínicas dos idosos institucionalizados. 
3. MÉTODOS 


\section{MÉTODOS}

\subsection{TIPO DE ESTUDO}

A presente pesquisa constitui um estudo epidemiológico, transversal, analítico, exploratório, com abordagem quantitativa. ${ }^{45}$

\subsection{PROCEDIMENTOS ÉTICOS}

O projeto de pesquisa foi registrado no Sistema Nacional de Informações sobre Ética em Pesquisa envolvendo Seres Humanos (Sisnep) que, por sua vez, o encaminhou ao Comitê de Ética em Pesquisa da Escola de Enfermagem da Universidade de São Paulo. O projeto obteve aprovação segundo o processo $\mathrm{n}^{0}$ 21612113400005392. Nas ILPI, o projeto foi submetido para apreciação das coordenações administrativas das Instituições e a autorização solicitada por meio de carta enviada pela autora (APÊNDICE I).

Somente após a aprovação do projeto em todas as instâncias, iniciouse a coleta de dados. Para tanto, os participantes do estudo foram esclarecidos acerca dos objetivos da pesquisa e, ao aceitarem participar, receberam e assinaram duas vias do Termo de Consentimento Livre e Esclarecido - TCLE (APÊNDICE II), elaborado conforme as normas da Resolução 196/96, que versa sobre os aspectos éticos em pesquisa envolvendo seres humanos. Após assinatura, uma das vias ficou com o participante e a outra com a pesquisadora. Ao participante, foram resguardados os direitos de anonimato e de interrupção de sua participação no projeto, quando conveniente. Para aqueles residentes que não se encontraram em condições de assinar o TCLE, seus cuidadores (formal ou informal) foram orientados acerca do estudo e assinaram o TCLE quando aceitaram a participação. 


\subsection{LOCAL DO ESTUDO}

O estudo foi realizado em três ILPI do município de São Paulo, que aceitaram participar do estudo.

Para a Agência Nacional de Vigilância Sanitária ${ }^{46}$, ILPI são instituições governamentais ou não governamentais, de caráter residencial, destinadas a domicílio coletivo de pessoas com idade igual ou superior a 60 anos, com ou sem suporte familiar, e mantidas em condições de liberdade, dignidade e cidadania. $^{46}$ Seu regulamento técnico e normas de funcionamento foram aprovados pela Resolução da Diretoria Colegiada ANVISA (RDC 283) ${ }^{46}$. As ILPI são também conhecidas por denominações diversas como: abrigo, asilos, lar, casa de repouso, clínica geriátrica, residências para idosos, ancianato. ${ }^{47}$ Embora seja comum associar ILPI a instituições de saúde, essas constituem estabelecimentos voltados a moradia, alimentação e vestuário, apesar de os residentes receberem também serviços de saúde e medicamentos. ${ }^{47}$

Em estudo realizado entre 2007 e $2009,{ }^{47}$ encontraram-se cerca de 84 mil residentes em ILPI, o que correspondia a menos de $1 \%$ da população idosa brasileira. Em outro estudo, ${ }^{48}$ empreendido pelo Instituto de Pesquisa Econômica Aplicada (IPEA) em parceria com o Conselho Nacional de Desenvolvimento Científico e Tecnológico ( $\mathrm{CNPq})$, o Ministério de Desenvolvimento Social e Combate à Fome (MDS), a Secretaria Especial de Direitos Humanos da Presidência da República (SEDH/PR), o Conselho Nacional dos Direitos do Idoso (CNDI) e a Faculdade de Saúde Pública da Universidade de São Paulo (USP), encontraram-se 2.255 ILPI na região sudeste do país, das quais 2.035 participaram da pesquisa. $\mathrm{O}$ estudo mostrou ainda que o estado de São Paulo possuía o maior número de ILPI no país, totalizando 1219 identificadas (84,5\% das quais responderam à pesquisa) e 276 instituições no município de São Paulo (214 respondentes). ${ }^{48}$

Para o presente estudo, o recrutamento das ILPI baseou-se no cadastro das instituições que participaram do estudo mencionado anteriormente. ${ }^{48}$ Em janeiro de 2013, foram realizadas tentativas de contato telefônico e de envio de mensagens eletrônicas para as 214 ILPI que 
responderam à pesquisa original. Dessas, 135 responderam ao primeiro contato e somente 19 mostraram interesse inicial em participar do estudo. Posteriormente, em agosto de 2013, após novo contato telefônico realizado com as 135 ILPI acessadas, em que se reiteraram os objetivos e procedimentos do estudo, somente os coordenadores de três ILPI ratificaram seu interesse, compondo a amostra de instituições para o presente estudo.

Neste estudo, as ILPI são intituladas e identificadas por letras (A, B e C), preservando-se o sigilo ético quanto às suas denominações. A instituição A, na zona Sul de São Paulo, particular e destinada somente para mulheres, caracteriza-se por ser uma casa térrea, naturalmente preparada para a terceira idade. Possui um jardim, onde as residentes podem desfrutar de todos os benefícios de um ambiente em contato com a natureza e o sol. Possui dois quartos grandes e três menores. Conta com uma equipe completa composta pelos serviços de administração, limpeza, cozinha, jardinagem, manutenção, enfermagem, nutrição e de hospedagem fixa, diária e de final de semana.

A instituição B, também particular, localizada na zona Norte de São Paulo, atua há 6 anos no atendimento de homens e mulheres a partir dos 60 anos. Possui uma casa térrea adaptada, com área externa para banho de sol, quartos planejados e separados por sexo. Conta com enfermeira e equipe de enfermagem, médico geriatra, cuidadores, nutricionista, fisioterapeuta, terapeuta ocupacional, fonoterapeuta e serviço de lavanderia terceirizado.

A instituição C, sem fins lucrativos, situa-se na zona leste de São Paulo e foi fundada em 1972 por um grupo de vicentinos preocupados com famílias carentes e idosos abandonados. A área física é extensa, com jardim e horta, dispondo de 60 leitos, distribuídos igualmente entre homens e mulheres em 20 quartos (três camas em cada quarto), com dois banheiros coletivos, um para cada sexo; conta também com área para banho de sol, sala de televisão coletiva e refeitório. Quanto aos recursos humanos, a instituição dispõe de enfermagem nas 24 horas, serviços de fisioterapia e nutrição, além de voluntariado. 


\subsection{POPULAÇÃO / AMOSTRA}

A população do estudo foi constituída de 77 idosos que residiam nas ILPI no momento da coleta de dados.

A amostra foi de conveniência, composta de 69 idosos residentes nas ILPI que atenderam os seguintes requisitos:

- ter idade igual ou superior a 60 anos; e

- aceitar participar do estudo (o próprio idoso ou o responsável).

A exclusão de oito idosos deveu-se à idade inferior a 60 anos (seis) e não estar presente na ILPI no momento da coleta, devido à internação hospitalar (dois).

A distribuição da amostra encontra-se representada na Tabela 1.

Tabela 1: Distribuição da amostra segundo a ILPI. São Paulo, 2013.

\begin{tabular}{cc}
\hline Instituição & $\boldsymbol{N}$ \\
\hline $\mathbf{A}$ & 22 \\
$\mathbf{B}$ & 12 \\
$\mathbf{C}$ & 35 \\
\hline
\end{tabular}

\subsection{COLETA DE DADOS}

Os dados foram coletados pela própria pesquisadora, após aprovação do projeto de pesquisa pelo Comitê de Ética em Pesquisa da Escola de Enfermagem da Universidade de São Paulo e autorização pelas ILPI que aceitaram participar do estudo.

\subsubsection{Procedimentos para a coleta de dados}

Após aprovação do projeto pelo Sisnep, a pesquisadora visitou cada ILPI, onde foi recebida pela coordenação administrativa que autorizou a coleta de dados e a encaminhou para a enfermeira responsável pela ILPI. A coleta de dados foi iniciada somente após a apresentação dos objetivos e procedimentos da pesquisa para a coordenação administrativa e enfermeira responsável técnica pela ILPI. 
Após essa etapa inicial, em cada ILPI, a enfermeira responsável apresentou a pesquisadora à sua equipe e, posteriormente, aos idosos residentes.

Os dados foram coletados mediante consulta ao prontuário, entrevista com o próprio residente e/ou responsável e exame físico do idoso.

Os residentes que atenderam aos critérios de inclusão foram entrevistados e avaliados quanto aos aspectos sócio-demográficos e clínicos, condições da pele e quanto às características das LF encontradas. Caso o próprio residente não conseguisse responder à entrevista, seu cuidador (formal ou informal) foi solicitado a fazê-lo.

Os dados referentes às doenças (Diabetes Mellitus - DM, Hipertensão Arterial Sistêmica - HAS, insuficiência venosa periférica e insuficiência arterial periférica), à acuidade visual e à história prévia de quedas e de LF, bem como o tempo e dose do emprego de corticóides e antiagregantes plaquetários, foram coletados mediante consulta em prontuários institucionais e informação verbal do residente e/ou cuidador.

Ainda quanto aos dados clínicos, para o cálculo do Índice de Massa Corporal (IMC), o peso foi obtido utilizando-se uma balança eletrônica, tipo portátil; e a estatura, por meio de um antropômetro com escala de precisão de $0,1 \mathrm{~cm}$. No caso do residente apresentar limitações para ficar em pé ou para locomover-se, utilizaram-se estimativas indiretas, por meio das equações preditivas de Chumleaet al, ${ }^{49,50}$ respectivamente, para o peso e estatura (Quadro 2).

\section{Quadro 2 - Equações para estimativas indiretas de peso e estatura.}

\begin{tabular}{|c|}
\hline Estimativa indireta do peso \\
\hline $\begin{array}{l}\text { Mulheres: P }(\mathrm{kg})=[1,27 \times \mathrm{CP}(\mathrm{cm})]+[0,87 \times \mathrm{AJ}(\mathrm{cm})]+[0,98 \times \mathrm{CB}(\mathrm{cm})]+[0,4 \times \mathrm{PCSE}(\mathrm{cm})]- \\
62,35\end{array}$ \\
\hline $\begin{array}{l}\text { Homens: } \mathrm{P}(\mathrm{kg})=[0,98 \times \mathrm{CP}(\mathrm{cm})]+[1,16 \times \mathrm{AJ}(\mathrm{cm})]+[1,73 \times \mathrm{CB}(\mathrm{cm})]+[0,37 \times \mathrm{PCSE}(\mathrm{mm})]- \\
81,69\end{array}$ \\
\hline $\mathrm{P}=$ peso, $\mathrm{CP}=$ circunferência da panturrilha, $\mathrm{AJ}=$ altura do joelho, \\
\hline $\mathrm{CB}=$ circunferência do braço, $\mathrm{PCSE}=$ prega cutânea subescapular, $\mathrm{CA}=$ circunferência abdominal \\
\hline
\end{tabular}




\section{Estimativa indireta da estatura}

Mulheres brancas: A $(\mathrm{cm})=70,25+[1,87$ x AJ $(\mathrm{cm})]-[0,06$ x I (anos)].

Mulheres negras: $\mathrm{A}(\mathrm{cm})=68,1+[1,86 \times \mathrm{AJ}(\mathrm{cm})]-[0,06 \times \mathrm{I}(\operatorname{anos})]$.

Homens brancos: $\mathrm{A}(\mathrm{cm})=71,85+[1,88 \times \mathrm{AJ}(\mathrm{cm})]$.

Homens negros: A $(\mathrm{cm})=73,42+[1,79 \times$ x AJ $(\mathrm{cm})]$.

$\mathrm{A}=$ altura, $\mathrm{AJ}=$ altura do joelho, $\mathrm{I}=$ idade

Posteriormente à entrevista, avaliaram-se a capacidade cognitiva, por meio do teste Mini Exame do Estado Mental (ANEXO I), e a independência para as atividades de vida diária, por meio da Escala de Katz (ANEXO II).

Após a aplicação do Mini Exame do Estado Mental e da escala de Katz, os residentes foram submetidos ao exame físico estático (para inspeção e palpação da pele) e dinâmico (para avaliação de rigidez, espasticidade, mobilidade física e marcha).

A inspeção e palpação da pele visaram à busca de LF, de algumas condições dermatológicas (púrpura senil, pele seca e descamativa, equimoses e hematomas), de algumas condições circulatórias (edema nos membros superiores e inferiores) e da presença de fitas e curativos adesivos. Com o intuito de sistematizar o exame físico estático da pele e não deixar de avaliar qualquer região do corpo, a examinadora respeitou sempre a mesma sequência de avaliação. Primeiramente, o residente foi posicionado em decúbito dorsal, para inspeção da cabeça, tórax, abdome, genitais, membros superiores e inferiores. E, a seguir, em decúbito ventral para inspeção da cabeça, dorso, glúteos, membros superiores e inferiores.

No exame físico dinâmico, avaliaram-se a rigidez, a espasticidade, a mobilidade física e a marcha.

A rigidez foi avaliada por meio de movimentação passiva e lenta dos membros superiores e inferiores. Constatou-se presença de rigidez em presença de resistência, ao longo de todo o trajeto do movimento, ao flexionar ou estender um membro (fenômeno chamado "cano de chumbo"). ${ }^{51-53}$ 
A espasticidade foi avaliada mediante movimentação passiva rápida dos membros superiores e inferiores. Foi constatada a presença de espasticidade quando houve aumento da resistência no início do movimento com consequente diminuição da resistência ao longo de todo o trajeto do movimento (fenômeno chamado "canivete"). ${ }^{51-53}$

A mobilidade física e a marcha foram avaliadas por meio de observação da deambulação do residente em linha reta, por um período de 30 segundos. Cadeirantes e acamados tiveram essas funções consideradas como alteradas.

\subsubsection{Instrumentos para a coleta de dados}

Quatro instrumentos foram utilizados para a coleta de dados.

\section{- Instrumento de coleta de dados sócio-demográficos e clínicos}

$\mathrm{O}$ primeiro instrumento de coleta de dados incluiu duas partes e destinou-se à coleta de dados sócio-demográficos e clínicos (APÊNDICE III).

A primeira parte objetivou a obtenção dos dados sóciodemográficos: iniciais do nome, registro na instituição, sexo, idade, raça, escolaridade, renda e tempo de permanência na ILPI. E a segunda, aos dados clínicos dos idosos: peso, altura, DM, HAS, doença vascular periférica (insuficiência venosa e insuficiência arterial), uso de corticóide, uso de antiagreganteplaquetário, história prévia de lesão por fricção, condições atuais da pele (presenças de equimose, hematomas nas extremidades, pele seca e descamativa e púrpura senil), edema de extremidades, rigidez e espasticidade, utilização de dispositivos invasivos, fitas e curativos adesivos, quedas, acuidade visual e utilização de órteses e próteses.

O estado nutricional foi avaliado por meio do Índice de Massa Corporal (IMC), segundo os critérios da Organização Mundial da Saúde $(\mathrm{OMS})^{54}$, para fins de comparação com estudos internacionais (Quadro 3). 
Quadro 3 - Classificação Internacional de IMC, segundo a OMS.

\begin{tabular}{|l|l|}
\hline Classificação & $\mathrm{IMC}\left(\mathrm{Kg} / \mathrm{m}^{2}\right)$ \\
\hline Baixo Peso & $<18,5$ \\
\hline Magreza Grave & $<16,0$ \\
\hline Magreza Moderada & $16,0-16,99$ \\
\hline Magreza Leve & $17,0-18,49$ \\
\hline Faixa Normal & $18,50-24,99$ \\
\hline Sobrepeso & $\geq 25,0$ \\
\hline Pré Obeso & $25,0-29,99$ \\
\hline Obeso & $\geq 30,0$ \\
\hline Obesidade classe I & $30,0-34,99$ \\
\hline Obesidade classe II & $35,0-39,99$ \\
\hline Obesidade classe III & $\geq 40,0$ \\
\hline
\end{tabular}

Teste Mini Exame do Estado Mental - MEEM

Para avaliação da capacidade cognitiva do residente, utilizou-se o teste Mini Exame do Estado Mental - MEEM (ANEXO I).

O MEEM foi desenvolvido por Folsteine, Folsteine e McHugh, ${ }^{55} \mathrm{em}$ 1975, e traduzida por Bertolucci et $a 1,{ }^{56}$ em 1994. Ele é composto de questões tipicamente agrupadas em sete categorias e fornece informações sobre diferentes parâmetros cognitivos. Objetiva avaliar funções cognitivas específicas como: orientação temporal, orientação espacial, registro de três palavras, atenção e cálculo, recordação das três palavras, linguagem e capacidade construtiva visual. A pontuação varia de 0 a 30 . Pontuação igual ou inferior a 12 revela comprometimento cognitivo, e pontuação igual ou maior a 13 , preservação cognitiva. ${ }^{57}$

\section{$\checkmark$ Escala de Katz}

A escala de Katz ou Escala de Independência em Atividades da Vida Diária (EIAVD) é uma das escalas mais citadas e utilizadas para avaliar a independência para as atividades da vida diária. Foi desenvolvida por Katz e colaboradores, ${ }^{58}$ em 1963, para a avaliação dos resultados de tratamentos em idosos e predição prognóstica nos doentes crônicos. Avalia seis funções sociobiológicas: tomar banho, vestir-se, transferência, controle esfincteriano, continência e alimentação. Neste estudo, duas dessas funções - incontinência e transferências - são avaliadas somente por meio da Escala de Katz e constituem variáveis importantes do estudo, ao serem 
consideradas como fatores associados à LF, além da própria independência para as atividades de vida diária como um todo. O Índice de Katz foi publicado e modificado por Katz e Akpon, em 1976, ${ }^{59}$ e traduzido para o Brasil por Lino e colaboradores $^{60}$ (ANEXO II). Nessa versão modificada, a classificação do índice ocorre pelo número de funções nas quais o indivíduo avaliado é dependente. A escala varia de 0 a 6 , sendo considerados 0 como independente e 6 como dependente. Entre 1 e 5 diminui a independência e aumenta a dependência em número de funções. Para este estudo, considerarse-á dependente qualquer indivíduo que apresentar diminuição da independência (escores de 1 a 6 ). ${ }^{58-61}$

\section{- Sistema de Classificação STAR - Lesão por Fricção $o^{3,4}$}

Para a avaliação e classificação das LF detectadas nos idosos, utilizou-se o Sistema de Classificação STAR - Lesão por Fricção, versão traduzida e adaptada para o Brasil. ${ }^{3,4}$ (ANEXO III )

O sistema de classificação STAR - Lesão por Fricção, desenvolvido por Carville e colaboradores ${ }^{2}$, é uma proposta originária da revisão da classificação de Payne e Martin ${ }^{1}$, que inclui cinco categorias de LF:

- Categoria 1a - Lesão por fricção cujo retalho de pele pode ser realinhado à posição anatômica normal (sem tensão excessiva) e a coloração da pele ou do retalho não se apresenta pálida, opaca ou escurecida;

- Categoria $1 b$ - Lesão por fricção cujo retalho de pele pode ser realinhado à posição anatômica normal (sem tensão excessiva) e a coloração da pele ou do retalho apresenta-se pálida, opaca ou escurecida;

- Categoria 2a - Lesão por fricção cujo retalho de pele não pode ser realinhado à posição anatômica normal (sem tensão excessiva) e a coloração da pele ou do retalho não se apresenta pálida, opaca ou escurecida;

- Categoria 2b - Lesão por fricção cujo retalho de pele não pode ser realinhado à posição anatômica normal (sem tensão excessiva) e a coloração da pele ou do retalho apresenta-se pálida, opaca ou escurecida; e

- Categoria 3 - Lesão por fricção cujo retalho de pele está completamente ausente. 
Esse instrumento foi adaptado culturalmente e validado para a língua portuguesa por Strazzieri-Pulido e Santos, em 2010. Ele é composto de três partes: ${ }^{3,4}$

- Diretrizes do Sistema de Classificação STAR - Lesão por Fricção: seis tópicos relacionados aos cuidados com a ferida e a pele ao redor;

- Sistema de Classificação STAR - Lesão por Fricção: cinco fotografias relacionadas às respectivas descrições das categorias da LF (1a, 1b, 2a, 2b e 3). Avalia a presença/ausência do retalho de pele e sua viabilidade; e

- Glossário: traz as definições de lesão por fricção e de termos técnicos relacionados ao assunto.

\subsection{VARIÁVEIS DO ESTUDO}

As variáveis do estudo apresentam-se listadas no Quadro 4.

\section{Quadro 4- Variáveis do estudo.}

\begin{tabular}{|c|c|c|}
\hline \multicolumn{3}{|c|}{ VARIÁVEL DEPENDENTE } \\
\hline Lesão por Fricção & Variável Nominal & Presente / Ausente \\
\hline \multicolumn{3}{|c|}{ VARIÁVEIS INDEPENDENTES } \\
\hline \multicolumn{3}{|c|}{ DEMOGRÁFICAS } \\
\hline Sexo & Variável Nominal & Feminino / Masculino \\
\hline Idade & Variável Contínua & Em anos \\
\hline Raça & Variável Nominal & Branca/Não branca \\
\hline $\begin{array}{l}\text { Tempo de } \\
\text { institucionalização }\end{array}$ & Variável Discreta & Em dias \\
\hline \multicolumn{3}{|c|}{ CLÍNICAS } \\
\hline Corticóide & Variável Nominal & Usa/Não usa \\
\hline Dose de corticóide & Variável Discreta & Em mg \\
\hline $\begin{array}{l}\text { Antiagregante } \\
\text { plaquetário }\end{array}$ & Variável Nominal & Usa/ Não usa \\
\hline $\begin{array}{l}\text { Dose do antiagregante } \\
\text { plaquetário }\end{array}$ & Variável Discreta & Em mg \\
\hline Anticoagulante & Variável Nominal & Usa/ Não usa \\
\hline Dose do anticoagulante & Variável Discreta & Em mg \\
\hline $\mathbf{D M}$ & Variável Nominal & Sim/Não \\
\hline HAS & Variável Nominal & Sim/Não \\
\hline $\begin{array}{l}\text { Doença vascular } \\
\text { periférica }\end{array}$ & Variável Nominal & Sim/Não \\
\hline Estado nutricional & Variável Ordinal & $\begin{array}{l}\text { Magreza grave / magreza moderada / magreza leve / faixa } \\
\text { normal / sobrepeso / pré-obesidade / obesidade classe I / } \\
\text { obesidade classe II / obesidade classe III }\end{array}$ \\
\hline Estado cognitivo & Variável Nominal & Comprometido/Preservado \\
\hline Deficiência visual & Variável Nominal & Presente / Ausente \\
\hline Imobilidade & Variável Nominal & Presente / Ausente \\
\hline Rigidez & Variável Nominal & Presente / Ausente \\
\hline Espasticidade & Variável Nominal & Presente / Ausente \\
\hline $\begin{array}{l}\text { Atividades básicas de } \\
\text { vida diária (ABVD) }\end{array}$ & Variável Nominal & Dependente / Independente \\
\hline
\end{tabular}




\begin{tabular}{|l|c|c|}
\hline Púrpura senil & Variável Nominal & Presente / Ausente \\
\hline Pele seca e descamativa & Variável Nominal & Presente / Ausente \\
\hline Equimoses & Variável Nominal & Presente / Ausente \\
\hline Hematomas & Variável Nominal & Presente / Ausente \\
\hline $\begin{array}{l}\text { Edema nos membros } \\
\text { superiores }\end{array}$ & Variável Nominal & Presente / Ausente \\
\hline $\begin{array}{l}\text { Edema nos membros } \\
\text { inferiores }\end{array}$ & Variável Nominal & Presente Ausente \\
\hline $\begin{array}{l}\text { Utilização de cadeira de } \\
\text { rodas }\end{array}$ & Variável Nominal & Presente/Ausente \\
\hline $\begin{array}{l}\text { Presença de fitas e } \\
\text { curativos adesivos }\end{array}$ & Variável Nominal & Sim / Não \\
\hline História prévia de LF & Variável Nominal & \\
\hline
\end{tabular}

\subsection{ANÁLISE DOS DADOS}

Visto que avaliar a prevalência de LF constitui um dos objetivos deste estudo, faz-se necessário estabelecer uma definição e, desse modo, a forma de medi-la. Neste estudo, utilizou-se a prevalência-ponto, que é a proporção de indivíduos que apresentam uma condição clínica em determinado ponto do tempo. Portanto, pode ser entendida como um corte da população em determinado ponto no tempo. Nesse momento, determinase quem tem e quem não tem a LF. ${ }^{45}$

No cálculo da prevalência, o numerador abrange o total de pessoas que apresenta a condição específica (LF) em um período determinado, enquanto o denominador é a população total estudada no mesmo período. ${ }^{45}$

Para o seu cálculo, foi utilizada a seguinte fórmula:

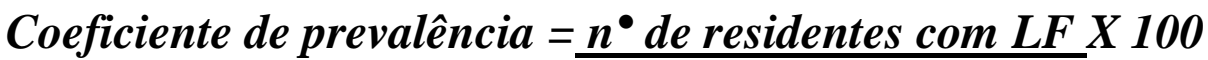 $n^{\circ}$ total de residentes}

Para a caracterização da amostra, os resultados são apresentados em frequências relativas e absolutas e, para as variáveis quantitativas, foram utilizadas médias e medianas. Na análise univariada, as associações entre a variável dependente e as variáveis independentes categóricas foram obtidas por meio do teste exato de Fisher e com as variáveis numéricas pelo teste de Wilcoxon-Mann-Whitney, com intervalo de confiança de $95 \%$. 
Posteriormente, todas as variáveis independentes que apresentaram nível de significância de $20 \%$ foram incluídas no modelo de regressão logística (backward stepwise), visando a identificar os fatores associados às LF.

Foram utilizados os softwares MS Office Excel versão 2007, para o gerenciamento do banco de dados; e SPSS versão 17.0, para a execução de todas as análises estatísticas.

Para o estudo foram considerados significativos os testes que obtiveram um nível descritivo menor que $5 \%(\mathrm{p}<0,05)$. 
4. RESULTADOS 


\section{RESULTADOS}

Os resultados são apresentados em forma de tabelas e foram divididos em: caracterização sócio-demográfica e clínica da amostra e prevalência e fatores associados ao desenvolvimento de LF em idosos institucionalizados.

\subsection{CARACTERIZAÇÃO DEMOGRÁGICA E CLÍNICA DA AMOSTRA}

Os dados sócio-demográficos e clínicos encontram-se na Tabela 2.

Tabela 2: Dados sócio-demográficos e clínicos dos idosos institucionalizados. São Paulo, 2013.

\begin{tabular}{|c|c|c|c|c|}
\hline \multicolumn{2}{|l|}{ Variáveis } & Média & \multirow{2}{*}{$\begin{array}{l}\mathbf{D P} \\
9,30\end{array}$} & \multirow{2}{*}{$\begin{array}{l}\text { Mediana } \\
82,00\end{array}$} \\
\hline Idade & & 81,74 & & \\
\hline Dose antiagregante $\mathrm{pl}$ & & 103,70 & 19,25 & 100,00 \\
\hline \multicolumn{2}{|c|}{ Tempo de institucionalização } & 1457,60 & 1935,46 & 728,00 \\
\hline & Categorias & $\mathbf{N}$ & $\%$ & \\
\hline \multirow[t]{2}{*}{ Sexo } & Masculino & 18 & 26,09 & \\
\hline & Feminino & 51 & 73,91 & \\
\hline \multirow[t]{2}{*}{ Raça } & Branca & 50 & 72,46 & \\
\hline & Não Branca & 19 & 27,54 & \\
\hline \multirow[t]{2}{*}{ DM } & Sim & 9 & 13,04 & \\
\hline & Não & 60 & 86,96 & \\
\hline \multirow[t]{2}{*}{ HAS } & Sim & 36 & 52,17 & \\
\hline & Não & 33 & 47,83 & \\
\hline \multirow[t]{2}{*}{ Doença vascular } & Sim & 12 & 17,39 & \\
\hline & Não & 57 & 82,61 & \\
\hline \multirow[t]{2}{*}{ Uso de corticóide } & Sim & 1 & 1,45 & \\
\hline & Não & 68 & 98,55 & \\
\hline \multirow{2}{*}{$\begin{array}{l}\text { Uso de antiagregante } \\
\text { Plaquetário }\end{array}$} & Sim & 27 & 39,13 & \\
\hline & Não & 42 & 60,87 & \\
\hline \multirow[t]{3}{*}{ Mobilidade } & Ambulante & 43 & 62,32 & \\
\hline & Cadeirante & 13 & 18,84 & \\
\hline & Acamado & 13 & 18,84 & \\
\hline \multirow[t]{3}{*}{ Marcha } & Normal & 11 & 15,94 & \\
\hline & Vacilante & 32 & 46,38 & \\
\hline & Não deambula & 26 & 37,68 & \\
\hline \multirow[t]{2}{*}{ Rigidez } & Presente & 28 & 40,58 & \\
\hline & Ausente & 41 & 59,42 & \\
\hline \multirow[t]{2}{*}{ Espasticidade } & Presente & 11 & 15,94 & \\
\hline & Ausente & 58 & 84,06 & \\
\hline \multirow[t]{3}{*}{ Acuidade visual } & Presente & 13 & 18,84 & \\
\hline & Diminuída & 32 & 46,38 & \\
\hline & Ausente & 24 & 34,78 & \\
\hline \multirow[t]{2}{*}{ Edema MMSS } & Presente & 2 & 2,90 & \\
\hline & Ausente & 67 & 97,10 & \\
\hline \multirow[t]{2}{*}{ Edema MMII } & Presente & 24 & 34,78 & \\
\hline & Ausente & 45 & 65,22 & \\
\hline
\end{tabular}




\begin{tabular}{|c|c|c|c|}
\hline & Categorias & $\mathbf{N}$ & $\%$ \\
\hline \multirow[t]{2}{*}{ Equimose } & Presente & 20 & 28,99 \\
\hline & Ausente & 49 & 71,01 \\
\hline \multirow{2}{*}{ Hematoma } & Presente & 9 & 13,04 \\
\hline & Ausente & 60 & 86,96 \\
\hline Pele seca e & Presente & 41 & 59,42 \\
\hline Descamativa & Ausente & 28 & 40,58 \\
\hline \multirow[t]{2}{*}{ Púrpura senil } & Presente & 16 & 23,19 \\
\hline & Ausente & 53 & 76,81 \\
\hline \multirow[t]{2}{*}{ Cadeira de rodas } & Presente & 28 & 40,58 \\
\hline & Ausente & 41 & 59,42 \\
\hline \multirow[t]{2}{*}{ Curativo/ adesivo } & Presente & 3 & 4,35 \\
\hline & Ausente & 66 & 95,65 \\
\hline \multirow[t]{2}{*}{ ABVD } & Presente & 52 & 75,36 \\
\hline & Ausente & 17 & 24,64 \\
\hline \multirow{2}{*}{ MEEM } & Comprometido & 51 & 73,91 \\
\hline & Preservado & 18 & 26,09 \\
\hline \multirow[t]{6}{*}{ Estado nutricional } & Magreza grave & 16 & 23,19 \\
\hline & Magreza moderada & 5 & 7,25 \\
\hline & Magreza leve & 5 & 7,25 \\
\hline & Normal & 24 & 34,78 \\
\hline & Sobrepeso & 18 & 26,09 \\
\hline & Obesidade & 1 & 1,45 \\
\hline \multirow[t]{2}{*}{ Incontinência } & Ausente & 24 & 34,78 \\
\hline & Presente & 45 & 65,22 \\
\hline
\end{tabular}

A amostra de 69 residentes foi composta predominantemente por mulheres $(51 / 73,91 \%)$, raça branca $(50 / 72,46 \%)$, com média de 81 anos de idade $(\mathrm{DP}=9,30)$ e mediana 82 anos, com algum problema na marcha (58/84,06\%), redução ou ausência na acuidade visual (56/81,16\%), dependência para ABVD (52/75,36\%), comprometimento cognitivo $(51 / 73,91 \%)$, presença de incontinência $(45 / 65,22 \%)$ e algum grau de desnutrição $($ magreza $=26 / 37,69 \%)$

Tabela 3: Variáveis quantitativas de acordo com a presença ou ausência de LF. São Paulo, 2013

\begin{tabular}{|c|c|c|c|c|c|c|c|c|c|}
\hline \multirow{3}{*}{ Variáveis } & \multicolumn{9}{|c|}{ Lesão por Fricção } \\
\hline & \multicolumn{4}{|c|}{ Presente } & & \multicolumn{3}{|c|}{ Ausente } & $p^{*}$ \\
\hline & $\mathrm{N}$ & $\begin{array}{l}\text { Média } \\
\text { (DP) }\end{array}$ & $\begin{array}{l}\text { Mín / } \\
\text { Max }\end{array}$ & Mediana & $\mathrm{N}$ & $\begin{array}{l}\text { Média } \\
\text { (DP) }\end{array}$ & $\begin{array}{l}\text { Mín / } \\
\text { Max }\end{array}$ & Mediana & \\
\hline Idade & 8 & $\begin{array}{l}83,88 \\
(13,10)\end{array}$ & $\begin{array}{l}66 / \\
98\end{array}$ & 83.00 & 61 & $\begin{array}{l}81,52 \\
(8,81)\end{array}$ & $62 / 98$ & 82,00 & 0,626 \\
\hline $\begin{array}{l}\text { Dose antiagregante } \\
\text { plaquetário }\end{array}$ & 3 & $\begin{array}{l}100,00 \\
(0,00)\end{array}$ & $\begin{array}{l}100 / \\
98\end{array}$ & 100.00 & 24 & $\begin{array}{l}104,17 \\
(20,41)\end{array}$ & $\begin{array}{l}100 / \\
200\end{array}$ & 100,00 & 0,724 \\
\hline $\begin{array}{l}\text { Tempo de } \\
\text { institucionalização }\end{array}$ & 8 & $\begin{array}{l}879,38 \\
(829,81)\end{array}$ & $\begin{array}{l}23 / \\
2412\end{array}$ & 608.50 & 61 & $\begin{array}{l}1534,70 \\
(2029,99)\end{array}$ & $\begin{array}{l}70 / \\
10000\end{array}$ & 728,00 & 0,351 \\
\hline
\end{tabular}

*Teste de Wilcoxon-Mann-Whitney 
A Tabela 3 mostra que não houve diferença estatisticamente significativa entre os grupos, com e sem LF, quanto a idade e tempos de uso de antiagregante plaquetário e de institucionalização.

\subsection{PREVALÊNCIA DE LF E FATORES ASSOCIADOS}

Oito sujeitos apresentaram LF, implicando em prevalência global estimada de 11,6\% para essa amostra, com um total de 13 lesões. Onze $(84,6 \%)$ LF localizaram-se nos MMII e duas $(15,4 \%)$ nos MMSS. Dessas lesões, seis $(46,1 \%)$ eram categoria 3 , três $(23,1 \%)$ categoria $1 \mathrm{~b}$, duas $(15,4 \%)$ categoria $1 \mathrm{a}$, uma $(7,7 \%)$ categoria $2 \mathrm{a}$ e uma $(7,7 \%)$ categoria $2 \mathrm{~b}$. Não se conseguiu identificar a causa de qualquer LF, sendo desconhecida tanto pelo idoso como pelo seu cuidador.

A Tabela 4 mostra a prevalência de LF, segundo cada categoria das variáveis categóricas.

Tabela 4: Prevalência de LF de acordo com a variável categórica. São Paulo, 2013.

\begin{tabular}{|c|c|c|c|c|c|c|c|c|}
\hline \multirow[t]{4}{*}{ Variável } & \multicolumn{8}{|c|}{ Lesão por Fricção } \\
\hline & \multicolumn{4}{|c|}{ Presente } & \multicolumn{2}{|c|}{ Ausente } & & \\
\hline & & \multicolumn{2}{|c|}{ IC $95 \%$} & & \multicolumn{2}{|c|}{ IC $95 \%$} & \multirow[b]{2}{*}{ SUP. } & \multirow[b]{2}{*}{$p^{*}$} \\
\hline & Categoria & $N(\%)$ & INF. & SUP. & $N(\%)$ & INF. & & \\
\hline \multirow[t]{2}{*}{ Sexo } & Masculino & $4(22,22)$ & 3,01 & 41,43 & $14(77,78)$ & 58,57 & 96,99 & 0,192 \\
\hline & Feminino & $4(7,84)$ & 0,46 & 15,22 & $47(92,16)$ & 84,78 & 99,54 & \\
\hline \multirow{2}{*}{ Raça } & Branca & $5(10,00)$ & 1,68 & 18,32 & $45(90,00)$ & 81,68 & 98,32 & 0,675 \\
\hline & Não branca & $3(15,79)$ & - & 32,19 & $16(84,21)$ & 67,81 & 100,00 & \\
\hline \multirow[t]{2}{*}{$D M$} & Sim & $1(11,11)$ & - & 31,64 & $8(88,89)$ & 68,36 & 100,00 & 1,000 \\
\hline & Não & $7(11,67)$ & 3,55 & 19,79 & $53(88,33)$ & 80,21 & 96,45 & \\
\hline \multirow[t]{2}{*}{ HAS } & Sim & $5(13,89)$ & 2,59 & 25,19 & $31(86,11)$ & 74,81 & 97,41 & 0,712 \\
\hline & Não & $3(9,09)$ & - & 18,90 & $30(90,91)$ & 81,10 & 100,00 & \\
\hline \multirow[t]{2}{*}{ Doença vascular } & Sim & $2(16,67)$ & - & 37,76 & $10(83,33)$ & 62,24 & 100,00 & 0,621 \\
\hline & Não & $6(10,53)$ & 2,59 & 18,50 & $51(89,47)$ & 81,50 & 97,44 & \\
\hline \multirow{2}{*}{ Uso de corticóide } & Sim & - & & & $1(100,00)$ & & & 1,000 \\
\hline & Não & $8(11,76)$ & 4,10 & 19,42 & $60(88,24)$ & 80,58 & 95,90 & \\
\hline \multirow{2}{*}{$\begin{array}{l}\text { Uso de } \\
\text { antiagregante } \\
\text { plaquetário }\end{array}$} & Sim & $3(11,11)$ & - & 22,96 & $24(88,89)$ & 77,04 & 100,00 & 1,000 \\
\hline & Não & $5(11,90)$ & 2,11 & 21,69 & $37(88,10)$ & 78,31 & 97,89 & \\
\hline \multirow[t]{3}{*}{ Mobilidade } & Deambula & $4(9,30)$ & 0,62 & 17,98 & $39(90,70)$ & 82,02 & 99,38 & 0,440 \\
\hline & Cadeirante & $3(23,08)$ & 0,18 & 45,98 & $10(76,92)$ & 54,02 & 99,82 & \\
\hline & Acamado & $1(7,69)$ & - & 22,17 & $12(92,31)$ & 77,83 & 100,00 & \\
\hline \multirow[t]{3}{*}{ Marcha } & Normal & - & & & $11(100,00)$ & & & 0,532 \\
\hline & Vacilante & $4(12,50)$ & 1,04 & 23,96 & $28(87,50)$ & 76,04 & 98,96 & \\
\hline & Não Deambula & $4(15,38)$ & 1,51 & 29,25 & $22(84,62)$ & 70,75 & 98,49 & \\
\hline \multirow[t]{2}{*}{ Rigidez } & Presente & $4(14,29)$ & 1,33 & 27,25 & $24(85,71)$ & 72,75 & 98,67 & 0,706 \\
\hline & Ausente & $4(9,76)$ & 0,68 & 18,84 & $37(90,24)$ & 81,16 & 99,32 & \\
\hline \multirow[t]{2}{*}{ Espasticidade } & Presente & $1(9,09)$ & - & 19,74 & $27(90,91)$ & 80,26 & 100,00 & 1,000 \\
\hline & Ausente & $7(12,07)$ & 2,10 & 22,04 & $34(87,93)$ & 77,96 & 97,90 & \\
\hline
\end{tabular}


Continuação

\begin{tabular}{|c|c|c|c|c|c|c|c|c|}
\hline \multirow[t]{4}{*}{ Variável } & \multicolumn{8}{|c|}{ Lesão por Fricção } \\
\hline & \multirow[b]{3}{*}{ Categoria } & \multicolumn{2}{|c|}{ Presente } & \multicolumn{5}{|c|}{ Ausente } \\
\hline & & \multirow[b]{2}{*}{$N(\%)$} & \multicolumn{2}{|c|}{ IC $95 \%$} & \multicolumn{4}{|c|}{ IC $95 \%$} \\
\hline & & & INF. & SUP. & $N(\%)$ & INF. & SUP. & $p^{*}$ \\
\hline \multirow[t]{3}{*}{ Acuidade visual } & Preservado & $1(7,69)$ & - & 22,17 & $12(92,31)$ & 77,83 & 100,00 & 0,701 \\
\hline & Diminuída & $5(15,65)$ & 3,06 & 28,24 & $27(84,35)$ & 71,76 & 96,94 & \\
\hline & Ausente & $2(8,33)$ & - & 19,39 & $22(91,67)$ & 80,61 & 100,00 & \\
\hline \multirow[t]{2}{*}{ Edema MMII } & Presente & $5(20,00)$ & 4,00 & 36,00 & $19(80,00)$ & 64,00 & 96,00 & 0,128 \\
\hline & Ausente & $3(6,82)$ & - & 14,19 & $42(93,18)$ & 85,81 & 100,00 & \\
\hline \multirow[t]{2}{*}{ Edema MMSS } & Presente & - & & & $2(100,00)$ & & & 1,000 \\
\hline & Ausente & $2(11,94)$ & 4,29 & 19,59 & $67(88,06)$ & 80,41 & 95,71 & \\
\hline \multirow[t]{2}{*}{ Equimose } & Presente & $4(20,00)$ & 2,47 & 37,53 & $16(80,00)$ & 62,47 & 97,53 & 0,217 \\
\hline & Ausente & $4(8,16)$ & 0,49 & 15,83 & $45(91,84)$ & 84,17 & 99,51 & \\
\hline \multirow[t]{2}{*}{ Hematoma } & Presente & $4(44,44)$ & 11,98 & 76,90 & $5(55,56)$ & 23,10 & 88,02 & 0,008 \\
\hline & Ausente & $4(6,67)$ & 0,36 & 12,98 & $56(93,33)$ & 87,02 & 99,64 & \\
\hline \multirow{2}{*}{$\begin{array}{l}\text { Pele seca e } \\
\text { Descamativa }\end{array}$} & Presente & $8(19,51)$ & 7,38 & 31,64 & $33(80,48)$ & 68,35 & 92,61 & 0,018 \\
\hline & Ausente & - & & & $28(100,00)$ & & & \\
\hline \multirow[t]{2}{*}{ Púrpura senil } & Presente & $5(31,25)$ & 8,54 & 53,96 & $11(68,75)$ & 46,04 & 91,46 & 0,014 \\
\hline & Ausente & $3(5,66)$ & - & 11,88 & $50(94,34)$ & 88,12 & 100,00 & \\
\hline \multirow[t]{2}{*}{ Uso de Cadeira } & Presente & $5(17,86)$ & 3,67 & 32,05 & $23(82,14)$ & 67,95 & 96,33 & 0,255 \\
\hline & Ausente & $3(7,32)$ & - & 15,29 & $38(92,68)$ & 84,71 & 100,00 & \\
\hline \multirow[t]{2}{*}{ Curativo } & Presente & $1(33,33)$ & - & 86,67 & $2(66,67)$ & 13,33 & 100,00 & 0,313 \\
\hline & Ausente & $7(10,61)$ & 3,18 & 18,04 & $59(89,39)$ & 81,96 & 96,82 & \\
\hline \multirow[t]{2}{*}{$A B V D$} & Dependente & $7(13,46)$ & 4,18 & 22,74 & $45(86,54)$ & 77,26 & 95,82 & 0,669 \\
\hline & Independente & $1(5,88)$ & - & 17,06 & $16(94,12)$ & 82,94 & 100,00 & \\
\hline \multirow[t]{2}{*}{ MEEM } & Comprometido & $6(11,76)$ & 2,92 & 20,60 & $45(88,24)$ & 79,40 & 97,08 & 1,000 \\
\hline & Preservado & $2(11,11)$ & - & 25,63 & $16(88,89)$ & 74,37 & 100,00 & \\
\hline \multirow{6}{*}{$\begin{array}{l}\text { Estado } \\
\text { nutricional }\end{array}$} & Magreza Grave & $3(18,75)$ & - & 37,88 & $13(81,25)$ & 62,12 & 100,00 & 0,731 \\
\hline & Magreza Moderada & - & & & $5(100,00)$ & & & \\
\hline & Magreza Leve & $1(20,00)$ & - & 55,06 & $4(80,00)$ & 44,94 & 100,00 & \\
\hline & Normal & $2(8,33)$ & - & 19,39 & $22(91,67)$ & 80,61 & 100,00 & \\
\hline & Sobrepeso & $2(11,11)$ & - & 24,88 & $18(88,89)$ & 75,12 & 100,00 & \\
\hline & Obeso & - & & & $1(100,00)$ & & & \\
\hline \multirow[t]{2}{*}{ Incontinência } & Ausente & $3(12,50)$ & - & 25,73 & $21(87,50)$ & 74,27 & 100,00 & 1,000 \\
\hline & Presente & $5(11,11)$ & 1,93 & 20,29 & $40(88,89)$ & 79,71 & 98,07 & \\
\hline \multirow[t]{3}{*}{ Faixa etária } & 60 a 64 anos & - & & & $1(100,00)$ & & & 0,2045 \\
\hline & 65 a 74 anos & $4(23,53)$ & 3,40 & 43,70 & $13(76,47)$ & 56,30 & 96,60 & \\
\hline & 75 anos ou mais & $4(7,84)$ & 0,50 & 15,20 & $47(92,16)$ & 84,80 & 99,50 & \\
\hline
\end{tabular}

*Teste Exato de Fisher

A Tabela 4 mostra que os coeficientes de prevalência de LF foram superiores entre os homens $(22,22 \%)$, com idade entre 65 a 74 anos, não brancos $(15,79 \%)$ e entre aqueles com HAS, alterações na marcha (principalmente cadeirantes), rigidez, acuidade visual diminuída, edema de MMII, equimoses, hematoma, pele seca e descamativa, púrpura senil, curativos/ adesivos, dependência para as AVDB e magreza. No entanto, somente as presenças de hematoma, pele seca e descamativa e púrpura senil mostraram diferenças estatisticamente significativas entre os residentes com e sem LF. Destaca-se a característica descamativa e seca da pele presente em todos os residentes com LF. 
Tabela 5: Fatores associados à ocorrência das LF, Segundo regressão logística. São Paulo, 2013.

\begin{tabular}{lllll}
\hline & \multicolumn{4}{c}{ IC95\% } \\
Variável & $\boldsymbol{R C}$ & Inferior & Superior & Valor- $\boldsymbol{p}$ \\
\hline Hematoma & 9,159 & 1,515 & 60,398 & $\mathbf{0 , 0 1 7}$ \\
Púrpura senil & 6,265 & 1,165 & 39,241 & $\mathbf{0 , 0 3 3}$ \\
\hline
\end{tabular}

A Tabela 5 mostra que dois fatores mantiveram-se associados à ocorrência das LF nos idosos institucionalizados, após análise por meio de regressão logística: as presenças de hematoma e de púrpura senil. Ou seja, na presença de hematomas, a chance de apresentar LF aumenta nove vezes e, na presença de púrpura senil, essa chance aumenta seis vezes. 
5. DISCUSSÃO 


\section{DISCUSSÃO}

Trata-se do primeiro estudo nacional sobre prevalência de LF em idosos institucionalizados. Poucos são os estudos encontrados sobre essa temática na literatura internacional já que, há apenas 25 anos, os pesquisadores começaram a monitorá-la. Apesar de ser uma lesão associada à pele frágil e delgada, comum entre os idosos, especialmente os debilitados, existem poucas publicações sobre a epidemiologia das LF nessa população.

Neste estudo, a prevalência global de LF foi $11,6 \%$ e apenas os hematomas e a púrpura senil mostraram-se como fatores associados ao seu desenvolvimento.

A seguir, constatam-se coeficientes bastante distintos, seja em relação ao presente estudo, seja entre os próprios estudos, principalmente em função dos diferentes cenários em que os dados foram coletados.

Em recente revisão integrativa da literatura ${ }^{62}$, sobre a epidemiologia das LF, as autoras analisaram seis estudos acerca da prevalência de LF, sendo a maioria desenvolvida na Austrália e, predominantemente, em cenário hospitalar. Nessa revisão, os coeficientes variaram de 3,3\% a $17 \%$ entre pacientes hospitalizados e de 5,5\% a 19,5\% no domiciliar. Os fatores associados mais citados foram: idade avançada e dependência para ABVD. Nível de mobilidade, comportamento agitado, ausência de resposta e maior risco para úlcera por pressão também foram mencionados.

Tendo em vista a maior similaridade com o cenário das ILPI, no atendimento domiciliar, destacam-se dois estudos, ambos australianos. O primeiro, retrospectivo, realizado com 1146 pacientes de diversas faixas etárias, mostrou prevalência de 5,5\% para LF, excluindo-se as lesões de MMII, $^{2}$ o que certamente subestima o resultado. Diversos autores ${ }^{6,11,20,21}$ afirmam que essas lesões predominam em MMII entre pessoas mais independentes, durante a realização das atividades de vida diária. Ratliff e Fletcher $^{63}$ também verificaram que as LF eram mais frequentes nos MMII 
daqueles pacientes que deambulavam. Edwards et al ${ }^{6}$ encontraram $60 \%$ das LF nos MMII, à similaridade do presente estudo, no qual onze $(84,6 \%)$ das 13 LF encontradas localizaram-se nos MMII . Quanto ao segundo estudo, realizado com 492 veteranos de guerra, com 70 anos ou mais, identificou prevalência superior $(19,5 \%) .^{5}$ Ambos os resultados, portanto, mostram-se bastante distintos daquele constatado neste estudo $(11,6 \%)$.

Entre pacientes hospitalizados, o número de publicações é maior. Desse modo, também em estudo australiano, McEarlean e colaboradores ${ }^{9}$ constataram prevalência de 11\%, semelhante àquela por nós obtida, em 187 pacientes hospitalizados em unidades gerais; no entanto, o coeficiente foi superior ao ser analisada a ocorrência de LF somente na unidade geriátrica $(18,5 \%)$, na unidade respiratória $(21,6 \%)$ e na unidade de cuidados paliativos $(27 \%)$. Tais coeficientes poderiam ser explicados devido às alterações que ocorrem na pele com o envelhecimento, ${ }^{1-4,7,11,12,15,18,21,26,27,32-}$ 39,43 conforme descritas anteriormente, no capítulo da Introdução, para a unidade geriátrica; ao uso de corticoides na unidade respiratória, também justificado por diversos autores, ${ }^{1,2,11,18,44}$ ao provocar redução da espessura da pele e um certo grau de edema. ${ }^{22,64}$ Já a elevada prevalência em unidades de cuidados paliativos pode estar relacionada ao elevado grau de dependência para as ABVD e aos distúrbios nutricionais que esses pacientes apresentam. Ressalta-se que nenhum desses fatores encontrados pelos autores, nas unidades hospitalares citadas, permaneceu no modelo final de regressão logística aqui realizada. Em um hospital escola de cuidados terciários na Austrália, os autores ${ }^{8}$ identificaram prevalência de 9,4\%, com um total de $72 \mathrm{LF}$.

Ainda na Austrália, de onde provém o maior número de publicações sobre as LF, o projeto Wound West acontece desde 2007 e se propõe a auditar todas as feridas dos pacientes atendidos pelo sistema público de saúde da região ocidental daquele país. ${ }^{65,66}$ Entre 2007 e 2011, a prevalência das LF variou de 7,9\%, 10,8\%, 9,2\% e 9,6\%. Considerando-se que unidades similares com alguma população idosa, estão inseridas entre as instituições de saúde australianas analisadas, observa-se proximidade 
com o valor verificado no presente estudo. Ainda no projeto Wound West, coeficientes mais estáveis e mais baixos foram identificados nas instituições hospitalares: $5,5 \%, 6,7 \%, 5,9 \%$ e $5,9 \% .^{66}$

Na população infantil, em pacientes de até 17 anos hospitalizados, encontrou-se apenas um estudo norte-americano ${ }^{67}$ em que se obteve prevalência elevada de $17 \%$. Tendo em vista que a maioria das LF foi encontrada em crianças de zero a três meses de vida, sua ocorrência pode estar também relacionada à fragilidade da pele constatada nos extremos de idade, entre neonatos e idosos. Pois ao nascimento além de apresentar estrato córneo deficiente e junção dermo-epidérmica pouco desenvolvida, a derme no recém nascido é fina, contando com apenas $60 \%$ da espessura quando comparada à derme do adulto. ${ }^{67}$

O único estudo brasileiro ${ }^{25}$ sobre a temática traz uma prevalência de 3,3\% de LF em 157 pacientes oncológicos hospitalizados, constituindo o mais baixo coeficiente encontrado na literatura. Ressalta-se que 55\% dos sujeitos da pesquisa tinham idade $\geq 60$ anos.

Quanto aos fatores associados aqui constatados - hematomas e púrpura senil - verificaram-se elevados coeficientes $(44,44 \%$ e $31,25 \%)$. De acordo com Malone e colaboradores ${ }^{11}$, as LF, frequentemente, ocorrem próximas à púrpura senil. ${ }^{68,69}$ Ambos os fatores estão associados a pequenos traumas. O hematoma aumenta a fragilidade da pele, o que pode aumentar o risco de lesões. ${ }^{68}$ A púrpura senil ocorre em idosos com desnutrição cutânea e está associada à diminuição do suporte conjuntivo devida à atrofia da pele consequente ao envelhecimento natural cutâneo, particularmente em pele foto lesada. No idoso, a atrofia da pele evidencia-se pelo seu ressecamento e afinamento, com enrugamento, perda de elasticidade, frouxidão e fácil dilaceração (pele de papel de seda), características associadas à LF. ${ }^{69}$ Todos os idosos com LF apresentaram pele seca e descamativa. Alguns estudos 14,20,42,70-72 trazem o ressecamento da pele - característica do envelhecimento cutâneo - como um fator de risco para o desenvolvimento de LF, fator que também não se confirmou como associado à ocorrência de LF no presente estudo, porém esteve presente em todos aqueles com LF. 
Dentre os fatores significativamente associados às LF, Carville e colaboradores $^{2}$ também identificaram a púrpura senil e o hematoma, além de outros já descritos anteriormente. Os demais, embora investigados neste estudo e até presentes nos residentes da amostra (edema de MMII, dependência para ABVD e equimoses), tais variáveis não permaneceram no modelo final de regressão logística.

McGough-Csarny e Kopac ${ }^{12}$, em estudo de coorte realizado em 10 ILPI revelaram que idade avançada, sexo feminino, dependência para ABVD, comprometimento nutricional, demência, déficit cognitivo, mobilidade limitada e equimose estavam entre os fatores de risco associados à LF. Similarmente, no amplo estudo de coorte de Payne e Martin ${ }^{1}$, em 10 ILPI, as LF desenvolveram-se principalmente em residentes mulheres, com déficit cognitivo, mobilidade limitada e dependência para algumas ABVD. A maioria desses fatores foi identificada nos idosos com LF deste estudo, embora não confirmados como associados às LF.

Para White et $\mathrm{al}^{20}$, pacientes totalmente dependentes para ABVD são o grupo de maior risco para LF. Em seu estudo, eles verificaram que esses pacientes adquirem LF frequentemente durante as atividades do dia a dia: ao se vestirem, ao tomarem banho, durante os posicionamentos e transferências. Pacientes mais independentes constituem o segundo grupo de maior risco para LF, podendo apresentar edema, púrpura senil e equimoses. $\mathrm{E}$, finalmente, para os mesmos autores ${ }^{20}$, os deficientes visuais constituiriam o terceiro grupo de maior risco. Todos esses grupos incluem pessoas mais vulneráveis ao trauma, o que aumenta a chance de LF.

Quanto às $13 \mathrm{LF}$ aqui encontradas, verificou-se que seis $(46,1 \%)$ delas eram categoria 3, segundo a classificação $\operatorname{STAR}^{3,4}$. Em dois outros estudos, que empregaram o mesmo sistema de classificação, também predominaram as LF de categoria 3, sendo 6 dentre nove LF no estudo nacional com pacientes oncológicos hospitalizados, ${ }^{25}$ e no projeto Wound West ${ }^{65,66}$ em todos os anos $(27 \%, 31 \%, 31 \%$ e $24 \%$, respectivamente). Porém, nessa última pesquisa, ${ }^{65,66} \mathrm{em}$ instituições hospitalares, predominaram as categorias $2 \mathrm{a}(78 \%)$, 1a (71\%) e $1 \mathrm{~b}(74 \%)$. 
6. CONCLUSÃO 


\section{CONCLUSÃO}

A prevalência de lesões por fricção nos idosos residentes em três ILPI do município de São Paulo foi de 11,6\% e as presenças de hematomas e púrpura senil mostraram-se associadas ao desenvolvimento de LF, aumentando em nove e seis vezes, respectivamente, as chances dessas ocorrências. Detectaram-se $13 \mathrm{LF}$, das quais 84,6\% localizavam-se nos MMII; 46,1\% eram LF categoria 3, seguidas de $23,1 \%$ categoria $1 \mathrm{~b} ; 15,4 \%$ categoria $1 \mathrm{a}$ e $7,7 \%$ categorias $2 \mathrm{a}$ e $2 \mathrm{~b}$. 
7. CONSIDERAÇÕES FINAIS 


\section{CONSIDERAÇÕES FINAIS}

Como se pode observar, o número de estudos epidemiológicos sobre as LF é bastante escasso, seja qual for o cenário, tanto internacional como nacionalmente. Especialistas reconhecem a carência de evidências científicas em relação às LF e indicam a necessidade de mais estudos para elucidar não somente sua epidemiologia como, principalmente, sua prevenção e tratamento.

Esta pesquisa constituiu o primeiro estudo nacional sobre a prevalência de LF entre idosos institucionalizados. Apesar de sua relevância, reconhecem-se suas limitações principalmente no que tange ao número de ILPI e, consequentemente, à casuística do estudo. Inúmeras e infrutíferas tentativas foram realizadas no sentido de alcançar um número maior de instituições na cidade de São Paulo, ao se pretender apresentar um panorama das LF nesse tipo de instituição. Trata-se, portanto, de mais uma etapa para a divulgação de conceitos, da classificação, da etiologia e, principalmente, da epidemiologia desse tipo de lesão, incluindo os fatores associados. Espera-se que tais resultados possam motivar o desenvolvimento de protocolos de prevenção por parte das equipes de saúde, nos diferentes cenários, mesmo com a ausência de evidências que os fundamentam na atualidade.

A escassez de estudos sobre a temática acarretou dificuldades para a discussão dos achados. Por outro lado, o mesmo fato pode representar um avanço pela contribuição que, certamente, o estudo traz, especialmente à área da Estomaterapia.

Os resultados do estudo, ao serem socializados com os responsáveis pelas ILPI, presencialmente, e com a comunidade científica, após sua publicação, podem constituir o primeiro passo para a introdução desse tema não só dentro das ILPI como na construção de um sistema de saúde mais seguro. Pretende-se que a incidência de LF possa constituir um dos indicadores de qualidade da assistência em instituições de saúde e asilares, 
em um futuro bem próximo, assim como as UP já o são. Incluí-la na Política Nacional de Segurança do Paciente, nas Políticas de Atenção ao Idoso e na regulamentação das ILPI consistem em outros objetivos importantes para a saúde das populações, especialmente dos idosos, e marcos importantes para a Estomaterapia brasileira.

Finalmente, espera-se que o estudo possa constituir um modelo para a replicação de seu desenho no desenvolvimento de novas pesquisas visando a traçar um perfil epidemiológico das LF no nosso país, corroborando ou acrescentando novos fatores associados e de risco para seu desenvolvimento e melhorando, enfim, as evidências sobre o tema. 


\section{REFERÊNCIAS}

1. Payne R, Martin M. The epidemiology and management of skin tears in the older adult.Ostomy/wound Management 1990; 26(jan/feb):26-37.

2. Carville, K., Lewin, G., Newall, N., Haslehurst, P., Michael, R., Santamaria, N., Roberts, P. STAR: A consensus for skin tear classification. Primary Intention. 2007; 15(1): 8-25.

3. Pulido KCS. Adaptação cultural e validação do instrumento STAR Skin Tear Classification System, para a língua portuguesa no Brasil [dissertação]. São Paulo (SP): Escola de Enfermagem, Universidade de São 58aulo; 2010.

4. Pulido KS, Santos VLCG. Cultural adaptation and validation of STAR Skin Tear Classification System for Brazilians. Wound Ostomy Continence Nursing Journal 2011; 38(3S):S92.

5. Carville K, Smith JA. Report on the effectiveness of comprehensive wound assessment and documentation in the community. Primary Intent 2004; (12):41-8.

6. Edwards H, Gaskill D, Nash R. Treating skin tears in nursing home residents: a pilot study comparing four types of dressing. Int $\mathrm{j}$ NursPrac 1998; (4):25-32.

7. Morey P. Skin tears: a literature review. Primary Intention 2007; 15(3):122-9.

8. Morey P, Young J, Nikoletti S. The prevalence of skin tears within a Western Australian acute care setting. In AWMA 2004. $5^{\text {th }}$ National Conference: Celebreting 10 years, reflection and evolution. Hobart, Tasmania 2004.

9. McErlean B, Sandison S, Muir D, Hutchinson B, Humphreys W. Skin tear prevalence and management at one hospital. Primary Intent 2004; (12):83-8.

10.WoundsWest. Wounds in WA - the facts.Government of Western Australia, Department of Health. 2009. Disponível em: http://www.health.wa.gov.au/woundswest/facts/index.cfm

11. Malone M, Rozario N, Gavinski M, GoodwinJ. The epidemiology of skin tears in the institucionalised elderly. Journal of American Geriatric Society 1991; 39(6):591-595.

12. McGough-CsarnyJ, Kopac C. Skin tears in the institucionalised elderly: an epidemiological study. Ostomy/wound management 1998; 44(3A)(suppl) Marc:14s-24s.

13.Instituto Brasileiro de Geografia e Estatística - IBGE. Projeção da População do Brasil. Comunicação Social, nov. 2008. Disponível em: 
http://www.ibge.br/home/presidencia/noticias/noticia_impressao.php, acessado em 09/01/2012.

14. LeBlanc K, Baranoski S. Skin tears: State of the science: consensus statements for the prevention, prediction, assessment, and treatment of skin tears. Adv Skin Wound Care 2011; 24(9) 2-15.

15. Meuleneire F. Using a soft silicone-coated net dressing to manage skin tears. J Wound Care. 2002; 11(10):365-9.

16. Meuleneire F. The management of skin tears. Nursing Times 2003; 99(5):69-71

17. Payne R, Martin M. Defining and classifuing skin tears: need for a common language. Ostomywoundmanage. 1993; 39(5):16-20.

18. LeBlanc K, Christensen D, Orstead H, Keast D. Best practice recommendations for the prevention and treatment of skin tears. Wound Care Canada 2008;6(8):14-32;

19. LeBlanc K, Baranoski S, Holloway S, Langemo D. Validation of a new Classification System for Skin Tears. Advances in skin e wound care 2013;26(3):263-265.

20. White M, Karam S, Cowel b. Skin tears in frail elders: a practical approach to prevention. Geriatric Nursing 1994; 15(2):95-98.

21. Madhuri R. Skin and wound care: Important considerations in the older. AdvSkinWoundcare2008; (21):424-36; quis 437-8.

22. Everett S, Powell T. Skin tears - the underestimated wound. Primary Intent 1994; (2):8-30.

23. White W. Skin Tears: a descriptive study of the opinions, clinical practice and knowledge base of RNs caring for the aged in high care residential facilities. Prim Intention 2001:9(8): 138-49.

24. Kennedy P, Kerse N. Pretibial skin tears in older adults: a 2-year epidemiological study. Journal of the American Geriatrics Society.August 2011-vol. 59, no. 8 pag 1547-8.

25. Amaral, AF; Pulido KCS, Santos VLCG. Prevalência de lesões por friç̧ão em pacientes hospitalizados com câncer. Rev. Esc. Enferm. USP.[online]. 2012; vol.46, n.spe, pp. 44-50.ISSN 0080-6234.

26. BaranoskiS. Skin tears: Staying on guard against the enemy of frail skin.Nursing 2000; 30(9) Sept: 41-46.

27. Bryant RA, Bonnie SR. Examining Threats to skin integrity. Ostomy/wound management 2001;47(6) June:18-27. 
28. Wysocki A. Anatomy and physiology go skin and soft tissue. In: Bryant RA (ed) : Acute and Chronic Wounds; Nursing Management, $2^{\text {nd }}$ ed. St. Louis, Mo.: Mosby, 2000:1-15.

29. Baranoski S. Skin tear: the enemy of frail skin. Adv. Skin Wound care. 2000;May/June:123-126.

30. Thomas DR, Goode PS, LaMaster K, Tennyson T, Parnell LK. A comparison of an opaque foam dressing versus a transparent film dressing in the management of skin tears in institutionalized subjects. Ostomy Wound Manage. 1999; 45(6):22-8.

31. Bank D, Nix D. Preventing skin tears in a nursing and rehabilitation center: an interdisciplinary effort. OstomyWoundManage. 2006; 52(9):3846

32. Fechine BRA, Trompieri N. O processo de envelhecimento: as principais alterações que acontecem com o passar dos anos. Rev. Científica internacional 2012;1(7):106-132.

33. Nascimento LV. Dermatologia do idoso. In Cucé LC, Festa CN. Manual de dermatologia 2ed. São Paulo: Atheneu;2001. p. 537-42.

34.Uitto J. Understanding premature skin aging. N Engl J Med1997; (337):1463-5.

35. Souza DMST, Santos VLCG. Úlceras por pressão e envelhecimento. RevistaEstima 2006;4(1):36-44.

36.Baranoski S. Skin tears: guard against this enemy of frail skin. Nursing Management 2001; 32(8):25-31.

37.Fenske NA, Loer CW. Skin changes of aging: pathological implications. Geriatric. 1990; 45(3):27-35.

38.Selden S, Cowell B, fenno J. Skin tears: recoginizing and treating this growing problem. Skin Aging 2002; (10):55-60.

39. LeBlanc K, Christensen D, Orsted HL, Keast DH. Prevention and treatment of skin tears. Wound Care Canada 2008; 6(1):14-32.

40.ECRI, ISMP. Sample police on skin tear management. PatientSafetyAdvisory 2006.

41. SABE - Saúde Bem-estar e Envelhecimento - O Projeto Sabe no município de São Paulo: uma abordagem inicial/ Maria Lúcia Lebrão, Yeda A. de Oliveira Duarte. - Brasília: Organização Pan-Americana de saúde, 2003.

42.Lyons WL, Johnston CB, Covinsky KE, Resnick NM. Medicina geriátrica. In: Tierney Jr LM, McPhee JS, Papadakis MA. Diagnóstico e tratamento. São Paulo: Atheneu; 2004 
43. Irving V, Bethell E, Burtin F. Neonatal wound care: minimizing trauma and pain. Wounds 2006:2(1):33-41

44. Baranoski $S, 2003^{2}$. How to prevent and manage skin tears. Adv Skin Wound Care 2003; 16(5):268-70

45. Fletcher RH, Fletcher SW. Epidemiologia clínica: elementos essenciais. $4^{\mathrm{a}}$ ed. Porto Alegre, RS: Artmed; 2006.

46. ANVISA. Resolução da Diretoria Colegiada, 283, de 26 de setembro de 2005. Disponível em: <www.portalsaude.gov.br>, em 30 de março de 2013.

47.Camarano AA, Kanso S. As instituições de longa permanência para idosos no Brasil. Rev. bras. Estud. Popul.2010; 27(1) 232-235.

48.Camarano AA,et al. Características das instituições de longa permanência para idosos - Região sudeste.Instituto de Pesquisa Econômica Aplicada- Ipea. Rio de Janeiro, 2010. Disponível em: http://www.ipea.gov.br

49.Chumlea WC, Guo SML. Predictionof stature from knee for black and white adults and children with application to mobility impaired or handicapped persons. JADA, 1994; 94: 1385-1388.

50.Chumlea WC, et al. Nutritional Assesment of the elderly through Antropometry. Colombus: Ross Laboratory, 1987.

51.Barnes MP, Kent RM, Smlyen JK, Mc Mullen KM. Spasticity in multiple sclerosis Neurorehabil Neural Repair 2003;(17): 1766-70.

52.Meythaler JM. Concept of spastic hypertonia.Phys Med RehabilClinNAm 2001;12:725-32.

53.Vivancos-Matellano F, Pascual-Pascual SI, Nardi-Vilardaga J, MiquelRodriguez F, de Miguel-Leon I, Martinez-Garre MC, et al. [Guide to the comprehensive treatment of spasticity]. Rev Neurol. 2007;45(6):365-75.

54. World Health Organization. BMI Classification. Global Database on Body Mass index: World Health organization; 2013.

55. Folstein MF, Folstein SE, McHugh PR. Mini-Mental State: a practical method for grading the cognitive state of patients for the clinician. J Psychiat Res 1975;12:189-198.

56. Bertolucci PHF, Brucki SMD, Campacci SR, Juliano Y. O mini-exame do estado mental em uma população geral: impacto da escolaridade. ArqNeuropsiquiatr1994;52:1-7.

57. Icaza, M.C, Albala, C. Projeto SABE. MinimentalStateExamination (MMSE) delestudio de dementiaen Chile: análisis estatístico. OPAS, 1999: $1-18$. 
58.Katz S, Ford AB, moskowitz RW, Jackson BA, Jaffe MW. Studies of illness in the aged, The index of ADL: A standardized measure of biological and psychosocial function. JAMA 1963;21(185) 914-9

59. Katz S, Akpom CA. A measure of primary sociobiological functions.Int J Health Serv. 1976; 6(3):493-508.

60.Lino VTS, Pereira SRM, Camacho LAB, Filho STR, BuksmanS.Adaptação transcultural da Escala de Independência em Atividades da Vida Diária (Escala de Katz). Cad. Saúde Pública, Rio de Janeiro, 2008;24(1):103-112.

61. Duarte YAO, Andrade CL, Lebrão ML. O Índex de Katz na avaliação da funcionalidade dos idosos. RevEscEnferm USP2007; 41(2):317-25.

62. Pulido KCS, Peres GRP, Campanili TCGF, Santos VLCG. Prevalência de lesões por fricção e fatores associados. Rev Esc Enferm USP, 2014 (em julgamento).

63. Ratliff CR, Fletcher KR. Skin tears: a review of the evidence to support prevention and treatment. Ostomy Wound Manage. 2007; 53(3):32-4,36,38-40.

64. Xiaoti Xu BS, Kwan Lau MD, Breena R, Taira MD, Adam JS. The current management of skin tears. American Journal of Emergency Medicine 2009;27:729-33.

65. Santamaria N, Carville K, Prentice J. Woundswest: Identifying the prevalence of wounds within western Australia's public health system. EWMA Journal 2009; 9 (3): 13-8.

66. Wounds West Wound prevalence survey 2011. State Wide Overview Report. Retrieved in agosto 2014. Disponível em: http://www.health.wa.gov.au/woundswest/docs/wwwps_11_state_reprt.pdf

67. McLane KM, Bookout K, McCain J, Jefferson LS. The 2003 national pediatric pressure ulcer and skin breakdown prevalence survey: a multisite study. J. WoundOstomyContinenceNurs. 2004 Jul-Aug; 31(4):168-78.

68. Brandão, ES. Pele - Características anatomofisiológicas e principais lesões elementares. In: Enfermagem em dermatologia: cuidados técnicos, dialógicos e solidários. Rio de Janeiro: Cultura Médica, 2006.

69. Sampaio, SAP. Erupçòes Purpúricas. In: Dermatologia. São Paulo: Artes Médicas, 2ed., 2000.

70. Battersby L. Exploring best practice in the management of skin tears in older people. Nursing Times 2009; 105(16), early online publication. Disponível em www.nursingtimesnet em 10 julho 2009. 
71. Brilhart B. Pressure sore and skin tear prevention and treatment during a 10 month program. RehabilNurs 2005; 30(3):85-91.

72. Groom M, Shannon RJ, Chakravarthy D, Fleck CA. An evaluation of cost and effects of a nutrient-based skin care program as a component of prevention of skin tears in an extended convalescent center. J Wound Ostomy Continence Nurs 2010; 37(1):46-51. 


\section{APÊNDICES \\ APÊNDICE I - Carta para Solicitação da Autorização da Instituição em participar do Estudo}

São Paulo, de de 20

Ilmo. Sr.

Diretor Administrativo

Instituição Longa Permanência para Idosos

Sou, Giovana RibauPicolo Peres, aluna do Programa de Pós-Graduação em Enfermagem na Saúde do Adulto (PROESA) da Escola de Enfermagem da Universidade de São Paulo, nível Mestrado, sob orientação da ProfaDra Vera Lucia Conceição de Gouveia Santos, e estou desenvolvendo um estudo sobre Prevalência de lesões por fricção e fatores associados em instituições de longa permanência da cidade de São Paulo.

Dessa forma, venho mui respeitosamente, solicitar autorização para que a instituição dirigida por VSa participe do estudo, cujo projeto intitula-se PREVALÊNCIA E FATORES ASSOCIADOS ÀS LESÕES POR FRICÇÃO EM IDOSOS DE INSTITUIÇÕES DE LONGA PERMANENCIA (em anexo). Seu objetivo é estimar a prevalência de lesões por fricção e fatores associados nos idosos residentes em instituições de longa permanência do município de São Paulo. A relevância do estudo está no seu ineditismo no país e na possibilidade de ajudar a equipe de saúde desta e das demais instituições a estabelecerem medidas de prevenção na formação dessas lesões que são dolorosas e impactam negativamente na qualidade de vida das pessoas por elas acometidas.

Uma vez autorizada à coleta de dados, os procedimentos implicam na realização de entrevista e exame físico dos idosos que vivem na instituição (uma vez que aceitem fazer parte do estudo e após assinatura do termo de Consentimento Livre e Esclarecido), além de acesso aos seus prontuários para complementação de obtenção dos dados.

Em todo o processo, asseguramos que o nome da instituição será mantido em sigilo e somente os resultados gerais da pesquisa serão divulgados por meio de publicações e em congressos científicos. Por outro lado, antes de sua execução, o projeto será submetido à avaliação pelo Comitê de Ética em Pesquisa da Escola de Enfermagem da USP, iniciando-se a coleta dos dados somente após sua aprovação.

A participação no estudo é voluntária e não haverá nenhum tipo de prejuízo seja para a instituição seja ao residente que se recuse a participar.

\section{Responsáveis pela pesquisa}

- Nome: Giovana RibauPicolo Peres - investigador principal.

Cargo: Enfermeira Estomaterapeuta. Aluna do Programa de PósGraduação em Enfermagem na Saúde do Adulto (PROESA)

Telefone: (11) 20624075/ (11) 985272878 - E-mail: gipicoloenf@yahoo.com.br

- Nome: Vera Lúcia Conceição de Gouveia Santos - orientadora do estudo.

Cargo: Enfermeira Estomaterapeuta (TISOBEST). Profa Associada do Departamento de Enfermagem Médico-Cirúrgica

- Comitê de Ética em Pesquisa da Escola de Enfermagem da Universidade de São Paulo

Endereço: Rua Enéas de Carvalho Aguiar, 419 - Cerqueira César - CEP: 05403-000 - São Paulo - SP - Telefone: 3061-7548 -E-mail: edipesq@usp.br 
Contamos com a sua colaboração e agradecemos desde já. Ademais, estamos à disposição para esclarecer o que for necessário.

Giovana RibauPicolo Peres

Responsável pela pesquisa 


\section{APÊNDICE II - Termo de Consentimento Livre e Esclarecido}

\section{Responsáveis pela pesquisa}

- Nome: Giovana RibauPicolo Peres - investigador principal.

Cargo: Enfermeira Estomaterapeuta. Aluna do Programa de Pós-Graduação em Enfermagem na Saúde do Adulto (PROESA)

Telefone: (11) 20624075 / (11) 985272878

- Nome: Vera Lúcia Conceição de Gouveia Santos - orientadora do estudo.

Cargo: Enfermeira Estomaterapeuta (TISOBEST). Profa Associada do Departamento de Enfermagem Médico-Cirúrgica

- Comitê de Ética em Pesquisa da Escola de Enfermagem da Universidade de São Paulo

Endereço: Rua Enéas de Carvalho Aguiar, 419 - Cerqueira César - CEP: 05403-000 - São Paulo - SP - Telefone: 3061-7548 -E-mail: edipesq@usp.br

A. Registro dos esclarecimentos dos pesquisadores aos participantes da pesquisa ou responsáveis legais.

Nós, autoras do Projeto de Pesquisa apresentado ao Programa de Pós Graduação da Universidade de São Paulo, convidamos você a participar de uma pesquisa intitulada "PREVALÊNCIA E FATORES ASSOCIADOS ÀS LESÕES POR FRICÇÃO EM IDOSOS DE INSTITUIÇÕES DE LONGA PERMANÊNCIA".

Esta pesquisa, de duração prevista de aproximadamente dois anos, tem por objetivo verificar a frequência de aparecimento de lesões por fricção, essas lesões são normalmente rasa, pequenas e podem aparecer depois de batidas de braços e pernas em quinas de mesas, cadeiras, e analisar os fatores associados a essa ocorrência (doenças, medicamentos etc...), em pessoas idosas residentes em Instituições de Longa Permanência para idosos (ILPI) no município de São Paulo. Para tanto, faremos uma entrevista com o(a) Senhor(a), exame físico e consulta ao seu prontuário. Confirmamos que os dados obtidos serãoutilizadosapenas neste estudo, podendo os resultados ser apresentados em eventos e publicados em revistas científicas, mantendo o sigilo quanto ao seu nome ou local onde reside.

A participação no estudo é totalmente voluntária e o(a) Senhor(a) pode deixá-la a qualquer momento que desejar. Em qualquer momento, o(a) Senhor(a) terá acesso aosseusdadosna pesquisa, inclusive para sanarmos quaisquer dúvidas ou fazermos esclarecimentos.

O estudo não acarretará riscos ao(à)senhor(a). Algumas perguntas podem causar certo constrangimento, porém nenhum dano e serão garantidos a confidencialidade, o sigilo e privacidade das informações. Também não há compensação financeira relacionada à sua participação. Caso aceite participar, o(a) senhor(a) deverá assinar as duas vias deste termo de consentimento, sendo que uma ficará conosco e a outra será entregue ao(à)senhor(a).

Desde já agradecemos a sua atenção e ficamos à disposição para quaisquer esclarecimentos sobre a pesquisa.

\section{B. Autorização da participante ou responsáveis legais.}

Compreendo o objetivo desta pesquisa e concordo em participar de forma voluntária da mesma, entendendo que as informações serão confidenciais, que não haverá identificação nominal e que não sofrerei qualquer tipo de sanção ou prejuízo, caso desista de participar deste estudo.

Declaro que, após convenientemente esclarecido pelo pesquisador e ter entendido o que me foi explicado, consinto em participar do presente Projeto de Pesquisa.

\section{Dados do Participante}

Nome: RG:

Sexo:__ Data de nascimento:_____ Telefone: (__

Endereço:

Bairro: Cidade: CEP.

Dados do responsável legal

Nome:

Natureza (grau de parentesco, tutor, cuidador, etc):

Sexo:____ Data de nascimento:_______ Telefone: $(\ldots)$
Endereç__ Cidade:_ CEP:__
Bairro:__


Assinatura do residente/representante legal e Data

Assinatura da testemunha e Data

Declaro que obtive de forma apropriada e voluntária o Consentimento Livre e Esclarecido deste residente ou representante legal para a participação neste estudo.

Assinatura do responsável pelo estudo e Data:/ / 


\section{APÊNDICE III - Instrumento de coleta de dados sócio- demográficos / clínicos/ exame físico}

\begin{tabular}{|c|c|c|}
\hline Data: & $\mathrm{N}^{0}$ instrumento: & Prontuário: \\
\hline \multicolumn{3}{|l|}{ Instituição: } \\
\hline \multicolumn{3}{|c|}{ Iniciais do nome: } \\
\hline Idade (anos): & Sexo: $1 . \mathrm{M} \quad 2 . \mathrm{F}$ & Raça:1.branca2. Não branca \\
\hline \multicolumn{2}{|c|}{ Tempo de institucionalização (em dias): } & Escolaridade (emanos): \\
\hline \multicolumn{3}{|c|}{ Renda familiar mensal (em $\mathrm{n}^{0}$ de salários mínimos): } \\
\hline \multicolumn{2}{|c|}{ DM: 1. Sim2. Não } & HAS: 1. Sim2. Não \\
\hline \multicolumn{3}{|c|}{ Dç Vascular periférica: 1. Sim2. Não_ } \\
\hline \multicolumn{3}{|c|}{$\begin{array}{ll}\text { Uso de corticóide: } 1 \text {. Sim2. NãoDose: } & \text { Tempo de uso: }\end{array}$} \\
\hline \multicolumn{3}{|c|}{$\begin{array}{l}\text { Uso de antiagreganteplaquetário: 1. Sim2. NãoDose: } \\
\text { uso: }\end{array}$} \\
\hline \multicolumn{3}{|c|}{ Uso de Anticoagulante: 1. Sim2. NãoDose: } \\
\hline \multicolumn{3}{|c|}{ Mobilidade Física: 1. Deambula2. Cadeirante 3. Acamado } \\
\hline \multicolumn{2}{|c|}{ Marcha:1. Normal2. Vacilante3. Não deambula } & História prévia de LF: 1.sim2. Não \\
\hline \multicolumn{2}{|c|}{ Rigidez: 1. presente 2. Ausente } & Espasticidade: 1.presente2.Ausente \\
\hline \multicolumn{3}{|c|}{ Acuidade visual: 1.presente 2. Ausente } \\
\hline \multicolumn{2}{|c|}{ Edema MMSS:1. Sim2. Não } & Edema MMII:1. Sim2. Não \\
\hline \multicolumn{2}{|c|}{ Equimose: 1.Sim2. Não } & $\begin{array}{l}\text { Hematomas nas extremidades:1. } \\
\text { Sim2. Não }\end{array}$ \\
\hline \multicolumn{2}{|c|}{ Pele Seca e Descamativa:1. Sim2. Não } & Púrpura Senil: 1. Sim2. Não \\
\hline \multicolumn{2}{|c|}{ Uso de cadeira de rodas:1. sim2.não } & $\begin{array}{l}\text { Curativos Adesivos:1. Sim2. Não } \\
\text { Qual local? }\end{array}$ \\
\hline \multicolumn{3}{|c|}{ Dependência para ABVD:1.dependente2. Independente } \\
\hline \multicolumn{2}{|l|}{ Peso: } & Altura (em metros): \\
\hline \multicolumn{2}{|l|}{ IMC: } & Estado Nutricional: \\
\hline \multicolumn{3}{|c|}{ Índex de Katz:1.Independente (escore 0) 2.Dependete (escore 1-6) } \\
\hline \multicolumn{2}{|c|}{$\begin{array}{l}\text { MEEM:1. Comprometimento cognitivo (pontuação 0-12) } \\
\text { 13-30) }\end{array}$} & 2. Preservação cognitiva (pontuação \\
\hline \multicolumn{3}{|c|}{ Lesão por frição:1. Sim2. Não $\quad$ Se sim, preencher os dados abaixo } \\
\hline \multicolumn{3}{|c|}{ 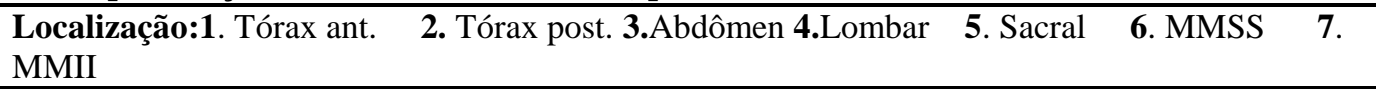 } \\
\hline \multirow{2}{*}{\multicolumn{3}{|c|}{\begin{tabular}{l|l} 
Tempo de ferimento (em dias): & Infecção: 1. Sim 2.Não \\
Condicão do retalho da pele:1. Viável2. Hematoma3. Isquemia4. Necrose5. Ausente
\end{tabular}}} \\
\hline & & \\
\hline \multirow{2}{*}{ 1. $1 \mathrm{a}$} & Classificação & \\
\hline & 2. $1 \mathrm{~b}$ & $4.2 b$ \\
\hline
\end{tabular}




\section{ANEXOS}

ANEXO1 - Mini-Exame do Estado Mental

\begin{tabular}{|c|c|}
\hline Data: & Registro na instituição: \\
\hline \multicolumn{2}{|l|}{ Instituição: } \\
\hline \multicolumn{2}{|l|}{ Nome completo: } \\
\hline \multicolumn{2}{|c|}{ Gostaria de fazer algumas perguntas sobre sua memória. } \\
\hline 1. Por favor me diga a data de hoje. & $\begin{array}{ll}\text { Mês: } & \text { Correto: } \\
\text { Dia: } & \text { Correto: }\end{array}$ \\
\hline $\begin{array}{l}\text { Pergunte mês, dia, ano e dia da } \\
\text { semana. } \\
\text { Anote um ponto em cada resposta } \\
\text { correta. }\end{array}$ & \begin{tabular}{lc} 
Ano: & Correto: \\
Dia da semana: & Correto: \\
Hora aproximada: & Correto: \\
(considere variação de mais ou menos uma hora) \\
\multicolumn{2}{c}{ Total: }
\end{tabular} \\
\hline $\begin{array}{l}\text { 2. Orientação espacial }- \text { pergunte ao } \\
\text { indivíduo: }\end{array}$ & $\begin{array}{l}\text { Em que local nós estamos? Correto: } \\
\text { (consultório, dormitório, sala - apontando para o } \\
\text { chão) }\end{array}$ \\
\hline Dê um ponto para cada resposta correta & $\begin{array}{l}\text { Que local é este aqui? Correto: } \\
\text { (apontando ao redor num sentido mais amplo: } \\
\text { hospital, casa de repouso, própria casa) } \\
\text { Em que bairro nós estamos ou qual o nome de } \\
\text { uma rua próxima? Correto: } \\
\text { Em que cidade nós estamos? Correto: } \\
\text { Em que Estado nós estamos? Correto: } \\
\text { Total: }\end{array}$ \\
\hline $\begin{array}{l}\text { 3. Agora vou lhe dar o nome de três objetos. } \\
\text { Quando eu terminar lhe pedirei que repita } \\
\text { em voz alta todas as palavras que puder } \\
\text { lembrar, em qualquer ordem. Guarde quais } \\
\text { são porque vou voltar a perguntar mais } \\
\text { adiante. O Sr (Sra) tem alguma pergunta? }\end{array}$ & $\begin{array}{l}\text { Árvore: } \\
\text { Mesa: } \\
\text { Cachorro: }\end{array}$ \\
\hline $\begin{array}{l}\text { Leia os nomes dos objetos devagar e de } \\
\text { forma clara somente uma vez. } \\
\text { 1. Repita todos os objetos até que o } \\
\text { entrevistado os aprenda. Máximo de } \\
\text { repetições: } 5 \text { vezes } \\
\text { 2. Anote o número de repetições que } \\
\text { teve que fazer }\end{array}$ & Número de repetições: \\
\hline
\end{tabular}




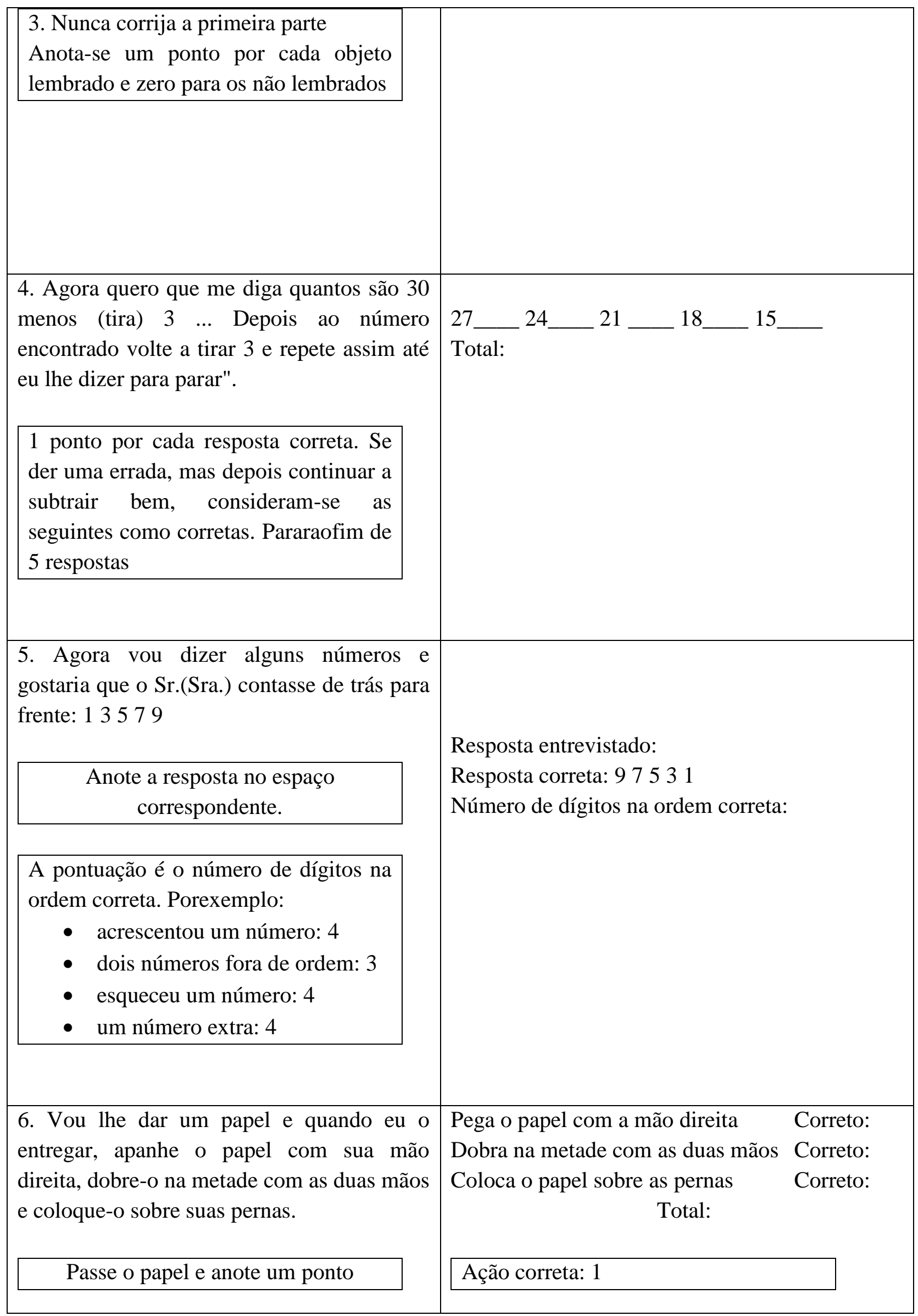




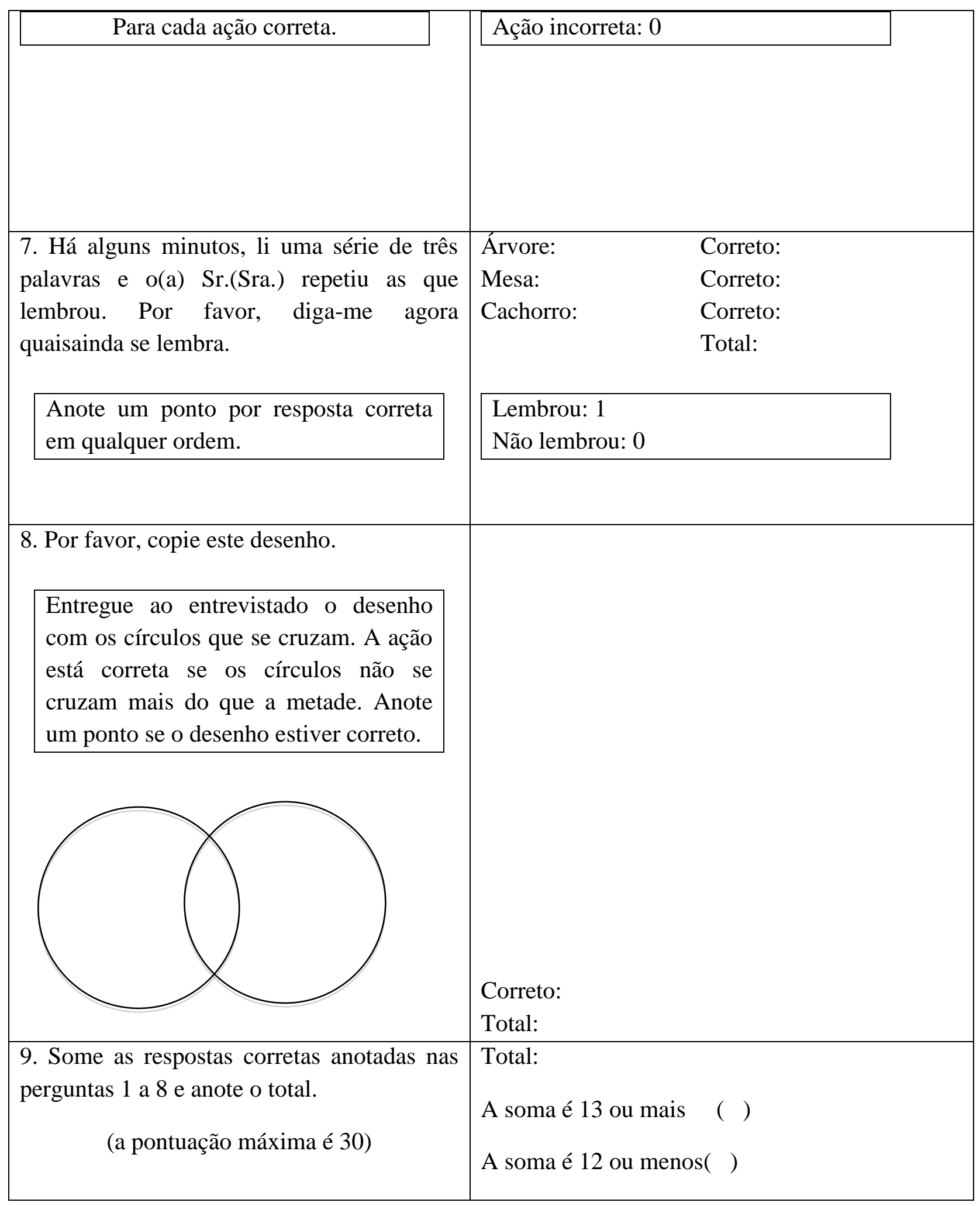




\section{ANEXO 2 - Índex de Katz Modificado}

\begin{tabular}{|l|l|l|}
\hline Data: & $\mathbf{N}^{0}$ instrumento: & Registro na instituição: \\
\hline Instituição: & \\
\hline Nome completo: & \\
\hline
\end{tabular}

Ficha de avaliação: para cada área de funcionamento listada abaixo assinale a descrição que se aplica (a palavra "ajuda" significa supervisão, orientação ou auxílio pessoal).

Área de funcionamento Independente/Dependente

Tomar banho (leito, banheira ou chuveiro)

( ) não recebe ajuda (entra e sai da banheira sozinho, se este for o modo habitual de tomar banho)

( ) recebe ajuda para lavar apenas uma parte do corpo (como, por exemplo, as costas ou uma perna)

( ) recebe ajuda para lavar mais de uma parte do corpo, ou não toma banho sozinho

Vestir-se (pega roupas, inclusive peças íntimas, nos armários e gavetas, e manuseia fechos, inclusive os de órteses e próteses, quando forem utilizadas)

( ) pega as roupas e veste-se completamente, (D) sem ajuda

( ) pega as roupas e veste-se sem ajuda, exceto para amarrar os sapatos

( ) recebe ajuda para pegar as roupas ou vestir-se, ou permanece parcial ou completamente sem roupa

Uso do vaso sanitário (ida ao banheiro ou local equivalente para evacuar e urinar; higiene íntima e arrumação das roupas)

( ) vai ao banheiro ou local equivalente, limpa-se e ajeita as roupas sem ajuda (pode usar objetos para apoio como bengala, andador ou cadeira de rodas e pode usar comadre ou urinol à noite, esvaziando-o de manhã)

( ) recebe ajuda para ir ao banheiro ou local 
equivalente, ou para limpar-se, ou para ajeitar as roupas após evacuação ou micção, ou para usar a comadre ou urinol à noite

( ) não vai ao banheiro ou equivalente para eliminações fisiológicas

\section{Transferência}

( ) deita-se e sai da cama, senta-se e levanta-se da cadeira sem ajuda (pode estar usando objeto para apoio, como bengala ou andador)

(D)

( ) deita-se e sai da cama e/ou senta-se e levanta-se da cadeira com ajuda

( ) nãosai da cama

\section{Continência}

( ) controla inteiramente a micção e a evacuação

( ) tem "acidentes" ocasionais

( ) necessita de ajuda para manter o controle da micção e evacuação; usa cateter ou é incontinente

\section{Alimentação}

( ) alimenta-se sem ajuda

( ) alimenta-se sozinho, mas recebe ajuda para cortar carne ou passar manteiga no pão

( ) recebe ajuda para alimentar-se, ou é alimentado parcialmente ou completamente pelo uso de catéteres ou fluidos intravenosos

Interpretação (Katz \&Apkom26): 0 : independente em todas as seis funções; 1: independente em cinco funções e dependente em uma função; 2 : independente em quatro funções e depen- dente em duas; 3: independente em três funções e dependente em três; 4 : independente em duas funções e dependente em quatro; 5: independente em uma função e dependente em cinco funções; 6: dependente em todas as seis funções. 


\section{ANEXO 3 - Sistema de Classificação STAR - Lesão por Fricção Sistema de Classificação STAR - Lesão por Fricção}

Diretrizes do Sistema de Classificação STAR - Lesão por Fricção

1. Controlar o sangramento e limpar a ferida de acordo com o protocolo institucional.

2. Realinhar (se possível) qualquer segmento de pele ou retalho.

3. Avaliar o grau de perda tissular e a cor da pele ou do retalho utilizando o Sistema de Classificação STAR - Lesões por Fricção.

4. Avaliar as condições da pele adjacente à ferida quanto a fragilidade, edema, descoloração e arroxeamento (aspecto de equimose).

5. Avaliar a pessoa, a(s) ferida(s) e a cicartização de acordo com o protocolo institucional.

6. Se a pele ou o retalho estiver pálido, opaco ou escurecido, reavaliar em 24-48 horas ou na primeira troca de curativo.

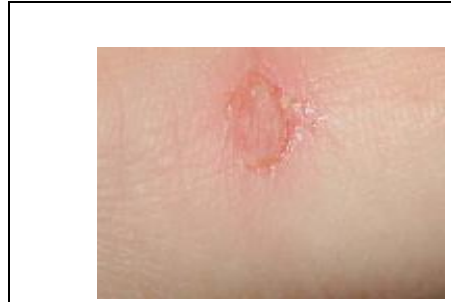

Categoria $1^{\text {a }}$

Lesão por fricção cujo retalho de pele pode ser realinhado à posição anatômica normal (sem tensão excessiva) e a coloração da pele ou do retalho não se apresenta pálida, opaca ou escurecida.

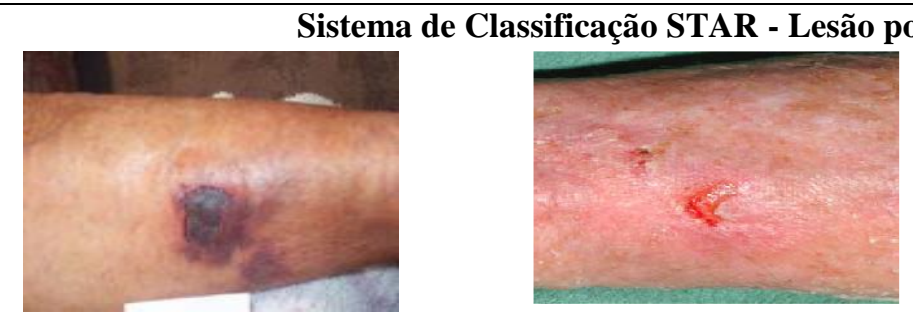

\section{Categoria 1b}

Lesão por fricção cujo retalho de pele pode ser realinhado à posição anatômica normal (sem tensão excessiva) e a coloração da pele ou do retalho apresentasepálida, opaca ou escurecida.

\section{Categoria 2a}

Lesão por fricção cujo retalho de pele não pode ser realinhado à posição anatômica normal (sem tensão excessiva) e a coloração da pele ou do retalho não se apresentapálida, opaca ou escurecida.

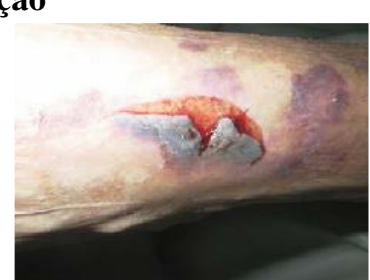

Categoria 2b

Lesão por fricção cujo retalho de pele não pode ser realinhado à posição anatômica normal (sem tensão excessiva) e a coloração da pele ou do retalhoapresenta-sepálida, opaca ou escurecida.

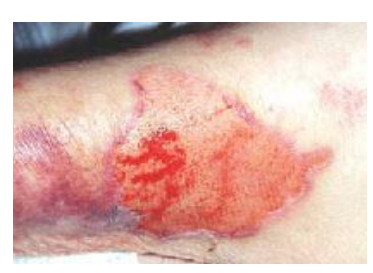

Categoria 3

Lesão por fricção cujo retalho de pele está completamente ausente. 


\section{Sistema de Classificação STAR - Lesão por Fricção}

\section{Glossário}

- Lesão por Frição: "ferida traumática que ocorre principalmente nas extremidades de idosos, resultante de fricção ou de uma combinação de fricção e cisalhamento, levando à separação da epiderme da derme (ferida de espessura parcial) ou separando totalmente a epiderme e a derme das estruturas subjacentes (ferida de espessura total)."

- Pele ou retalho de pele pálido, opaco ou escurecido: quando comparadaa pele "normal" do indivíduo ao redor da ferida pode indicar isquemia ou presença de hematoma, o que pode afetar a viabilidade da pele ou retalho.

- Isquemia: perfusão tissular inadaqueda evidenciada pela palidez, opacidade ou escurecimento do tecido.

- Hematoma: coleção de sangue ou coágulos sob um retalho ou pele realinhada.

- Realinhar: recolocar a pele ou retalho na sua posição anatômica normal sem tensão excessiva.

- Lesão por fricção linear: fissura ou rompimento da pele em linha reta.

- Retalho de pele: segmento de pele ou de pele e tecido subjacente separado das demais estruturas

\section{Referências:}

1 Payne, R., \& Martin, M. (1993). Defining and classifying skin tears: Need for a common language ... a critique and revision of the Payne-Martin Classification system for skin tears. Ostomy Wound Management, 39(5):16-20.

2 Photographs courtesy of the Skin Tear Audit Research (STAR) photographic library, Silver Chain Nursing Association and School of Nursing and Midwifery, Curtin University of Technology.

3 Carville, K., Lewin, G., Newall, N., Haslehurst, P., Michael, R., Santamaria, N., \& Roberts, P. (2007). STAR: A consensus for skin tear classification. Primary Intention, $15(1), 18-28$.

Copyright of original version: Skin Tear Audit Research (STAR). Silver Chain Nursing Association and School of Nursing and Midwifery, Curtin University of Technology. Revised 4/2/2010. Copyright of Brazilian's adapted and validated version of STAR: Strazzieri-Pulido e Santos 2010. 